AnUARIO DE Estudios MEdIEVALES 46/2, julio-diciembre de 2016, pp. 899-937

ISSN 0066-5061

doi:10.3989/aem.2016.46.2.10

\title{
CARESTÍA Y LUCHA POLÍTICA EN CASTILLA DURANTE EL SIGLO XV ${ }^{1}$
}

\author{
DEARTH AND POLITICAL STRUGGLE IN CASTILE \\ IN THE FIFTEENTH CENTURY
}

\author{
HiPÓlito RAFAEl OLIVA HERRER \\ Universidad de Sevilla
}

\begin{abstract}
Resumen: El siglo XV fue un periodo de crecimiento en la Corona de Castilla y sin embargo las carestías aparecieron de manera recurrente. Se analizan algunas de esas carestías para abordar el funcionamiento del mercado del grano y determinar los factores que inciden en el alza de precios. Un análisis comparado de la gravedad relativa de esas carestías demuestra que las más severas están relacionadas con factores de tipo político más que intrínsecamente productivos. El artículo analiza la dimensión conflictiva de esas disposiciones políticas, ya que los agentes percibieron y denunciaron los mecanismos que operaban en el mercado del cereal. En determinados contextos, llegaron a proponer regulaciones adicionales e incluso a protagonizar revueltas contra quienes se beneficiaban de la especulación en el mercado del grano.
\end{abstract}

Palabras clave: carestía; mercado del grano; conflicto social; Corona de Castilla; siglo $\mathrm{XV}$.

\begin{abstract}
The fifteenth century was a period of growth in the Crown of Castile and yet there were recurrent periods of dearth. Some of these episodes are examined in order to address the functions of the cereals market and determine the factors that contributed to a rise in prices. A comparative analysis of the relative importance of these shortages shows that the severest of them involved factors that were political in nature, rather than intrinsically related to production. This article analyzes the dimension of conflict that surrounded these political regulations, since the actors were aware of the mechanisms that operated in the cereals market and condemned them. In certain contexts, they went as far as to propose additional regulations and even to lead revolts against those who profited from speculation in the grain market.
\end{abstract}

Keywords: dearth; grain market; social conflict; Crown of Castile; XVth century.

${ }^{1}$ Este artículo recoge resultados obtenidos en el proyecto de investigación ¿El poder de la comunidad?: lenguaje y prácticas políticas populares a fines de la Edad Media. (HAR 201130035), financiado por el Ministerio de Economía y Competitividad del gobierno de España.

Abreviaturas: Archivo General de Simancas. Registro General del Sello = AGS. RGS; Archivo Municipal de Sevilla. Papeles del Mayordomazgo = Mayordomazgo. 


\section{SUMARIO}

1. Introducción.- 2. Analizando carestías en la primera mitad del XV: Sevilla y Burgos.- 3. Sobre la gravedad relativa de las carestías: precios del trigo en Burgos.4. Percepciones de la carestía y lucha política.- 5. Bibliografía citada.

\section{INTRODUCCIÓN}

El fenómeno de las carestías y hambres medievales está siendo objeto de renovada atención por la historiografía reciente ${ }^{2}$. El trabajo que sigue se sitúa en esa línea, tomando como punto de referencia el siglo XV en la Corona de Castilla ${ }^{3}$. La elección del siglo XV esta motivada por varios aspectos. No es el menos importante el de las fuentes conservadas. El más relevante, sin embargo, es la recurrencia de episodios de carestía durante un ciclo largo de crecimiento económico. Efectivamente, si algo caracteriza a la Corona de Castilla en relación a otros países Europeos, es lo temprano de su crecimiento en relación al estancamiento que se observa en otros lugares y sin embargo las carestías se sucedieron de manera regular durante este ciclo expansivo ${ }^{4}$.

El artículo pretende analizar los principales factores que provocaron esas carestías y determinar su gravedad, pero también abordar las percepciones de los agentes implicados. Desde este momento avanzo que muchos de estos episodios críticos en la coyuntura del XV están vinculados tanto a decisiones políticas como a los propios mecanismos de funcionamiento del mercado del cereal, esto es, más a factores humanos que naturales ${ }^{5}$, por lo que me interesa analizar en que medida este conjunto de fenómenos fueron objeto de denuncia y de enfrentamiento político.

\footnotetext{
${ }^{2}$ En particular, el análisis de las hambrunas en el tercer mundo en época contemporánea ha proporcionado elementos de reflexión que han sido incorporados al estudio del medievo. Las referencias más importantes, con algunas variaciones significativas, Sen 1981; Ravaillon 1987; Devereux 1993; Brunel 2002. También el importante trabajo de un medievalista que conjuga el análisis histórico y presente, Salrach 2012.

${ }^{3}$ Para una revisión reciente de los modelos aplicados por los medievalistas para el análisis de las carestías, Menant 2007 y Benito 2011. Son representativos del reciente interés de los medievalistas por el tema y del cambio de enfoques Bourin, Menant, Drendel 2011; Oliva 2007b; López 2011; Arízaga, Solórzano 2009.

${ }^{4}$ Sobre los ritmos del crecimiento, Ladero, González 1978; Casado 1991; Díaz de Durana 1990; Ladero1988b; Álvarez 1984; López, Martín 1981. También las interpretaciones de conjunto más recientes de Yun, 2004; Oliva 2007a.

${ }^{5}$ Sobre esta cuestión, Bourin et al. 2011; Menant 2007; Palermo 1997, pp. 240-241; Benito 2011, pp. 130-140.
} 


\section{ANALIZANDO CARESTÍAS EN LA PRIMERA MITAD DEL XV: \\ SEVILLA Y BURGOS}

El estudio de carestías durante el XV tiene una cierta tradición en Castilla. Disponemos de excelentes trabajos de autores como Miguel Ángel Ladero y Manuel González o Isabel Montes, para la Sevilla del XV, o de H. Casado para los obispados de Burgos y Palencia, e incluso de estudios que abordaron la relación entre carestía y conflicto social, tal es el caso de A. MacKay, por citar los más próximos al escenario de este artículo ${ }^{6}$. Este trabajo se beneficia de estos análisis previos y de su esfuerzo por recopilar datos de producción y de precios de cereal, que nos permiten plantear nuevos interrogantes acerca de los mecanismos de la carestía de acuerdo a la percepción actual de estos fenómenos, que se ha visto sustancialmente modificada ${ }^{7}$.

Sevilla ofrece una de las primeras referencias documentadas de crisis frumentaria para este periodo. Se trata de la crisis de los años 1412-1414, que ya mereciera atención por parte de Miguel Ángel Ladero y Manuel González ${ }^{8}$.

El relato del cronista Alvar García de Santa María contiene suficientes elementos para hacer una valoración. En un primer momento, alude el inicio de la carestía en 1413, como resultado de la mala cosecha. Aunque a continuación matizará este extremo, señalando que el hambre se produjo primero en Portugal y que es la exportación masiva de cereal a este lugar la que determina el alza del precio en Andalucía con bastante anterioridad a la propia cosecha.

E como en el Andalucía e en Sevilla había mucho pan, e en los lugares del maestrazgo de Santiago que comarcan con Portugal, bastecieron mucho los de Portugal del pan de Andalucía e de la tierra del maestre, en tal manera que antes que viesen si el pan sembrado el año de antes nacía comenzó la carestía de pan, en especial en Andalucía y en la tierra del maestre?

En realidad, el pan exportado a Portugal no fue el único cereal que salió de Andalucía ese año. En 1412, Fernando de Antequera obtuvo autorización regia para sacar al menos 50.000 fanegas de trigo con destino a Barcelona y Valencia ${ }^{10}$. De hecho, al referirse a la actividad del secretario de Cámara del rey de Aragón, el cronista relata la especulación asociada a la compra de grano

\footnotetext{
${ }^{6}$ Ladero, González 1978; Montes 2007; Casado 1991; MacKay 1972.

${ }^{7}$ Sobre el cambio de paradigma, Benito 2013.

${ }^{8}$ Ladero, González 1978, pp. 37-39.

${ }^{9}$ Carriazo 1947, p. 53.

${ }^{10}$ Ladero, González 1978, p. 38.
} 
a gran escala, probablemente superando las licencias concedidas y fuente de pingües beneficios.

Comenzó a cargar su pan en navíos para Aragón. E como quiera quél compro en el Andalucía mucho pan en nombre del Rey, lo menos envió al Rey, e vendió mucho dello en los lugares do lo compró, por muy gran precio en manera que aquí alcanzó muchos dineros ${ }^{11}$.

Sin duda el alza de precios, ya en 1412, debió motivar que en diciembre de ese año el concejo sevillano tratará de impedir la salida de más trigo para la Corona de Aragón ${ }^{12}$. Es en este contexto donde el cronista introduce nuevamente la mala cosecha como un factor agravante de la carestía.

E por ende, comenzó el Andaluzía la gran carestía de pan, primero que no en Castilla. E como sembraron y no cogieron subió mucho el pan en esta sazón, que llegó en Sevilla e en Córdoba a dos doblas la fanega, e más; e lo peor es que no se fallaba. E luego subió el pan en toda Castilla, e en el reino de Granada, e en Navarra ${ }^{13}$.

Su relato es interesante porque describe un modelo de contagio del alza de precios y extensión de la carestía, en otras palabras, una interrelación de los mercados que propicia que el alza del precio andaluz repercuta en buena parte del territorio peninsular. Más allá de este importante detalle, el cronista se muestra dubitativo en su explicación del fenómeno, ya que refiere la subida de precios y la espiral especulativa motivada por la exportación, para luego atribuir la responsabilidad a la mala cosecha en 1413.

En realidad, es bastante probable que la cosecha andaluza de 1413 e incluso la de 1414 no fueran buenas. Para el 1413 disponemos de la referencia cronística. La documentación sevillana alude además al 1414 como de esterilidad ${ }^{14}$. Pero incluso si así fuera, las evidencias tienden a indicar que los factores en el inicio de la crisis se sitúan al margen de la producción agraria, y que ésta, en todo caso, se vería agravada por las malas cosechas.

A este respecto, es bastante ilustrativa la comparación con los datos de producción y de precios que publicara para Hilario Casado Burgos ${ }^{15}$. La serie de precios del trigo en Burgos, no sólo confirma esta interrelación de mercados, sino que ratifica que el incremento de precios se había producido con bastante anterioridad a la mala cosecha de 1413 .

${ }^{11}$ Carriazo 1947, p. 53.

${ }^{12}$ Ladero, González 1978, p. 38.

${ }^{13}$ Carriazo 1947, p. 54.

${ }^{14}$ Mayordomazgo 1421, doc. 38.

${ }^{15}$ Casado 1991. 
La producción de cereal burgalesa entre 1410 y 1420 se mantuvo básicamente estable. Por lo que respecta a los precios, sólo se conserva para aquellos años la referencia al precio de 1412 que, sin embargo, es significativamente alto y se sitúa entre los cinco más elevados para la primera mitad de siglo. Por tanto, el alza de precios había comenzado a sentirse visiblemente en 1412, en un lugar tan alejado de Sevilla como Burgos, sin que la producción de su entorno hubiese experimentado una caída que la justificara.

El segundo gran episodio de carestía se produjo sólo unos años más tarde, entre 1420 y 1423. Para este periodo contamos ya con informaciones parciales sobre producción y precios en Sevilla lo que nos permite un análisis más detallado.

Tabla 1. Producción y precios en Sevilla (1417-1435)

\begin{tabular}{|c|c|c|}
\hline & $\begin{array}{c}\text { COSECHA DE TRIGO } \\
\text { ESTIMADA EN FANEGAS }\end{array}$ & $\begin{array}{c}\text { PRECIO DE LA FANEGA EN } \\
\text { REALES }\end{array}$ \\
\hline 1417 & & 1,99 \\
\hline 1418 & & 1,50 \\
\hline 1419 & 713992 & 1,86 \\
\hline 1420 & & 3,04 \\
\hline 1421 & 732396 & 4,14 \\
\hline 1422 & 748564 & 5,00 \\
\hline 1423 & & 5,43 \\
\hline 1424 & 885229 & 3,71 \\
\hline 1425 & 759914 & 3,36 \\
\hline 1426 & & 4,57 \\
\hline 1427 & & 2,43 \\
\hline 1428 & & 1,91 \\
\hline 1429 & 713129 & 1,29 \\
\hline 1430 & 1011824 & 1,89 \\
\hline 1431 & 1210693 & 1,44 \\
\hline 1432 & & \\
\hline 1433 & & \\
\hline
\end{tabular}

Fuente: Ladero, González 1978 
A pesar de lo limitado de la serie ofrecida por M.A. Ladero y M. González para esos años, no parece que las cosechas entre 1420 y 1423 fueran excesivamente reducidas. Más bien parecen situarse en una normalidad con variaciones lógicas de algo más de 700.000 fanegas por año, siendo lo excepcional las excelentes cosechas obtenidas en los años 1431 y 1432.

La documentación sevillana alude a la carestía y mengua de pan en Sevilla y su tierra en aquellos años. Pero esta referencia no implica asunciones respecto del volumen de la cosecha, sino más bien sobre la falta de disponibilidad de pan y la dificultad para adquirirlo, extremo que por otra parte corroboran los datos de precios.

No parece claro que se trate de un problema de producción, sino más bien de precio. De hecho, la carestía andaluza y particularmente la de Sevilla, fue abordada en las Cortes de Ocaña de 1422, celebradas en agosto. Desconocemos la producción de 1421, pero resulta ilustrativo que, en su denuncia, los procuradores no aludan a las malas cosechas. Antes al contrario, estiman que la de 1422 fue buena al señalar que si la merced de Dios non acorriera con el agua de abril este anno pasado, toda el Andaluzia estaua en peligro quese despoblara ${ }^{16}$.

La cosecha de 1423 superaría la del año anterior, aunque la serie de precios sevillana ofrece para este año el más elevado de la primera mitad del $\mathrm{XV}$. En realidad, la explicación proporcionada por los procuradores en Cortes apunta a fenómenos bien distintos en el origen de la carestía:

Alo que me pedistes por mercet diziendo quelos rreyes onde yo vengo, que Dios dé Santo Parayso, con mucha deligengia guardaron que del Andaluzia, e en especial de Seuilla e de su arcobispado, por la mar non se sacase pan (...) el Rey don Enrique, mi padre, que Dios de Santo paraiso, que en diversos tiempos por alguno de sus privados le fue demanda saca e que solo cient cafizes non dio. Et que yo que auia dado de tres annos acá mill cafizes poco mas o menos (...) Que de aqui adelante que se non sacase pan alguno, e que se diese sobre ello las cartas que menester fuesen para las cibdades e villas del Andaluzia, quelo non consientan sacar, e en especial para Seuilla e Xerez déla frontera ${ }^{17}$.

A juicio de los procuradores, el problema se encontraba en las licencias concedidas por la monarquía para la exportación del grano desde Andalucía. No ya sólo porque se reducía el cereal disponible sino porque, como veremos más adelante, la exportación alimentaba mecanismos especulativos que propiciaban una subida de precio.

\footnotetext{
${ }^{16}$ Cortes, vol. III, p. 38.

${ }^{17}$ Ibidem.
} 
Con todo, la cifra ofrecida por los procuradores en Cortes no comprende el conjunto del cereal salido de de la Baja Andalucía en aquellos años. Sólo en 1420, al menos 5.000 cahíces de trigo sevillano habían salido para Santander, para el abastecimiento de la $\operatorname{armada}^{18}$. La denuncia alude más bien, como el resto de las referencias a sacas de trigo en Cortes, a licencias de exportación concedidas a gentes que gozan del favor regio. Otra cuestión interesante tiene que ver con la referencia a las autoridades locales en las ciudades andaluzas, lo que sugiere que los integrantes de esos gobiernos locales detentaran a su vez algún tipo de interés en este tráfico comercial.

La documentación del mayordomazgo sevillano permite seguir las medidas implementadas por la ciudad para hacer frente al alza de precios. Este último extremo no contradice la anterior afirmación. El gobierno local podía tomar medidas, con independencia de que sus integrantes tuvieran intereses particulares, una vez que la escalada de precios hubiese alcanzado un punto peligroso para la estabilidad social ${ }^{19}$.

Significativamente, la documentación sevillana alude también a las licencias de saca al inicio de la carestía. El precio del trigo había comenzado a subir en 1420 y el alza era ya notable en 1421. El dos de julio de este último año, el concejo se dirigió al monarca para solicitar que no se llevasen a efecto las licencias de saca concedidas ${ }^{20}$. Por esas mismas fechas hay ya evidencias de acaparamiento. De hecho, en mayo, el propio concejo había encargado que se efectuara una pesquisa en Utrera, para ver quien había comprado pan ese año y el año anterior ${ }^{21}$. Paralelamente, el alza de precios había desencadenado mecanismos de bloqueo en la circulación de cereal. Así pues, el concejo tuvo que dirigirse a los de Córdoba, Écija y Palma del Río para que permitieran la salida de pan hacia Sevilla ${ }^{22}$. Ese mismo año de 1421 el concejo encargó a algunos de sus oficiales que vendieran trigo a los atahoneros de la ciudad y a ciertos vecinos, aunque desconocemos si el cereal era de su propiedad o había sido comprado a instancias de la ciudad ${ }^{23}$.

Los precios continuaron en ascenso en 1422. A comienzos de agosto, presumiblemente después de la cosecha o con esta muy avanzada, el concejo trató de facilitar la llegada de trigo de las tierras del maestrazgo de Santiago ${ }^{24}$. Sabemos también que, por aquellas fechas, el pan se vendía en la alhóndiga a

${ }^{18}$ Mayordomazgo, 1420, doc. 38.

${ }^{19}$ Sobre esta cuestión, Bourin et al 2011, pp. 473-474.

${ }^{20}$ Mayordomazgo, 1421, doc. 10.

${ }^{21}$ Ibidem, 1420, doc. 110.

${ }^{22}$ Ibidem, 1421, doc. 10.

${ }^{23}$ Ibidem, 1422, doc. 117.

${ }^{24}$ Ibidem, 1422, doc. 48. 
precio fijado por el concejo ${ }^{25}$. Sin embargo en diciembre de ese mismo año, la documentación municipal alude nuevamente a la carestía y mengua de pan, de ahí que se comisionara nuevamente un enviado a Córdoba, para facilitar el acceso de pan desde esta ciudad. Es bastante más revelador que este mismo personaje fuera además enviado para visitar los lugares de la Campiña, para hacer venir a la ciudad el pan que pudiese ${ }^{26}$. De hecho, la Campiña era uno de los principales graneros tradicionales sevillanos y sin embargo el pan no acudía a la ciudad en diciembre, como tampoco lo estaba haciendo antes, esperando un incremento de precio más que probable en los meses subsiguientes. En definitiva, se trataba de un problema de especulación.

En el año de 1423, momento álgido de la subida de precios, las medidas fueron más allá. De entrada, a comienzos de año el concejo declaró libre de alcabalas la venta de pan en la alhóndiga, con la intención de atraer el pan a la ciudad ${ }^{27}$. Dado que los incentivos a la venta no parecieron funcionar en la medida deseada, el concejo recurrió a medidas coercitivas, obligando a algunos vecinos de la propia ciudad a poner a la venta sus stocks y efectuando un repartimiento obligado de trigo entre los lugares de su propia jurisdicción ${ }^{28}$. Esto es, el desabastecimiento se solucionó mediante recursos que estaban en la propia ciudad y su entorno, y que sin embargo no habían salido a la venta.

Paralelamente se procedió a la regulación de las ventas en la alhóndiga. El concejo envió a uno de los jurados de la ciudad para que fiscalizara las transacciones viendo la manera de que la gente del pueblo pudiese alcanzar dicho pan al mejor precio que pudiese ${ }^{29}$. De lo que se trataba es de evitar que el precio subiese. Más que de un problema de falta de trigo, parece que nos encontremos ante uno de dificultad de acceso debido al precio elevado, esto es, ante un esquema similar a los definidos en la literatura del entitlement aproach $^{30}$.

De hecho, la misión del jurado sevillano de control de la alhóndiga fue prorrogada después de la cosecha, para impedir que el acaparamiento y las compras masivas de grano volvieran a incidir nuevamente en el precio, esto es para que no se sacase mas pan del que cada uno necesitase segun su estado y para procurar que el precio de la fanega no subiese. ${ }^{31}$

\footnotetext{
${ }^{25}$ Ibidem, 1422, doc. 60.

${ }^{26}$ Ibidem, 1422, doc. 99.

${ }^{27}$ Ibidem, 1523, doc. 37.

${ }^{28}$ Ibidem, 1423, doc. 48.

${ }^{29}$ Ibidem, 1422, doc. 116.

${ }^{30}$ Particularmente, Sen 1981; Palermo 1997.

${ }^{31}$ Mayordomazgo, 1423, doc 110.
} 
En suma, la documentación sevillana ofrece la imagen de un proceso especulativo de alza de precios y retención de stocks, que tiene su origen en las licencias a la exportación concedidas por el monarca y que prefiguran ya un alza de precios. Es bastante revelador que la documentación aluda constantemente a este episodio como la carestía y mengua de pan, estableciendo una diferencia con el año de 1414, al que refiere como de esterilidad ${ }^{32}$.

Sin embargo, más allá de esta referencia a esterilidad en el año 1414 o de la mala cosecha en 1413, no parece haber grandes diferencias en el origen del ciclo de carestía entre 1412-1414 y 1420-1423, dado que en ambos casos la espiral de precios se inicia con las licencias de saca. En la explicación de porqué la exportación de cereal genera alzas de precios concurren varios factores. La propia salida de los stocks tiene su incidencia y la compra de cereal en gran cantidad propicia ya una subida de precios. Documentación más tardía parece confirmar este proceso ${ }^{33}$.

Aunque sin duda el elemento más influyente parece ser la expectativa de beneficios de los agentes ${ }^{34}$. Ante la perspectiva de una situación de stocks más reducidos comienzan a acaparar excedentes y a retirar el cereal, esperando y de hecho provocando que el precio suba. La aparición de una mala cosecha durante el periodo de alza de precios potenciará sin duda los efectos, pero no está necesariamente en el origen.

El alza de precios relacionada con la exportación del trigo volvería a reproducirse en Andalucía y en Sevilla en particular a lo largo de XV. La Baja Andalucía era una región productora y en muchos casos exportadora de cereal y en torno a ello concurrían intereses muy complejos y a menudo contradictorios. No se ha llamado la atención, sin embargo, sobre el impacto de esta política de exportación en el precio del cereal en el conjunto del reino.

Este impacto puede medirse en parte comparando las series de precios sevillana y burgalesa en la primera mitad del XV. Existen algunos problemas, pues los datos burgaleses son de precios máximos anuales, mientras que la serie sevillana recoge precios medios, aunque ello no obsta para que ambas series sean ilustrativas de tendencias. Lo incompleto de las series tampoco impide observar que más allá de variaciones lógicas, existió en esos años una elevada correlación de precios.

\footnotetext{
${ }^{32}$ Ibidem, 1421, doc. 38.

${ }^{33}$ Así, por ejemplo, en 1477, Francisco Bocanegra beneficiario de una concesión de licencia de saca de 6.000 cahíces protestaba porque le querían vender a mayor precio del que el trigo tenía en ese momento, AGS. RGS. X - 1477, f. 436.

${ }^{34}$ Sobre estas cuestiones, Persson 2004, pp. 47-62; Benito 2011, pp. 133-136.
} 
Gráfico 1. Precios del trigo, Sevilla/Burgos (1417/1439)

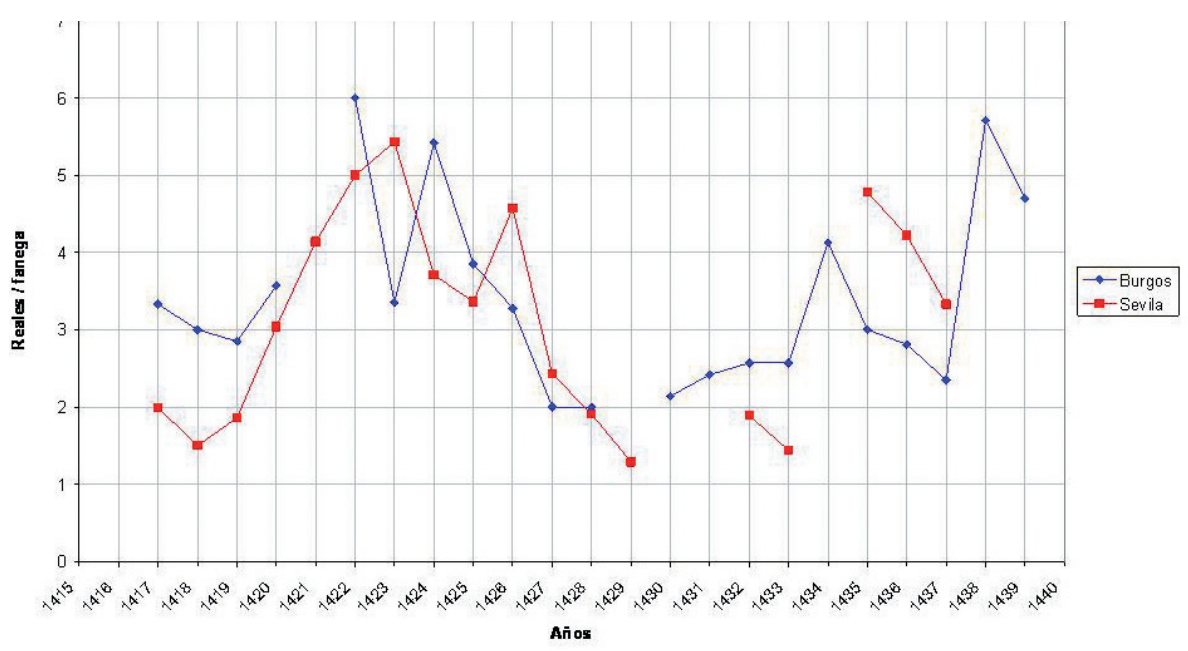

Fuente: Ladero, González 1978; Casado 1991. Elaboración propia.

La correlación parece clara respecto del alza de precios de los años 1420-1423. La escalada perceptible en Sevilla se reproduce en Burgos, donde se alcanzó el pico máximo del precio del cereal para la primera mitad del XV en 1422. Esto es, coincidiendo con la denuncia de las sacas desde Andalucía efectuada en las Cortes de Ocaña. Dado que, como ya señalé, no existen grandes oscilaciones en la producción agraria en la comarca burgalesa entre 1410 y $1422^{35}$, parece claro que el fenómeno refleja el impacto del precio del cereal en Andalucía.

El problema de la integración de mercados es un asunto que generalmente se ha enfocado para fechas más tardías. ${ }^{36}$ El debate, está lejos de estar cerrado, aunque las tendencias más recientes apuntan a una cierta integración ya para mediados del siglo XVII, momento en que se puede contar con series completas de precios que permiten la comparación ${ }^{37}$. Las condiciones del transporte terrestre hacían inviables tráficos habituales en distancias largas, aunque esto no fue obstáculo para que plazas alejadas sin intercambio directo de mercancías, participaran de una interrelación de precios. La explicación radica en los flujos de intercambio en distancias cortas y medias en los itine-

\footnotetext{
${ }^{35}$ Casado 1991, p. 73.

${ }^{36}$ Para una revisión historiográfica Llopis 2001, pp. 13-68.

${ }^{37}$ Llopis, Sotoca 2005, pp. 225-262.
} 
rarios que conectan esas ciudades, pero también en los flujos de información entre mercados, fenómeno especialmente apropiado para analizar episodios de carestía ${ }^{38}$.

Sin obviar las conexiones marítimas habituales entre el espacio sevillano y la cornisa cantábrica, que se abastecía muy frecuentemente del trigo andaluz y en ocasiones acudía al cereal de la meseta ${ }^{39}$, las interrelaciones de precios entre la serie burgalesa y la sevillana pueden ser interpretadas a la luz de este modelo, máxime teniendo en cuenta que las condiciones del acarreo del grano no debieron haber experimentado transformaciones sustanciales.

Lo que también parece claro es que los contemporáneos fueron conscientes de que la exportación del cereal tenía un impacto sobre el conjunto del territorio. Sólo desde esta perspectiva pueden entenderse proclamaciones como la efectuada en los capítulos de la Junta comunera en Tordesillas a la altura de 1520 , en los que se prohibía la exportación de cereal con referencia particular a Sevilla como centro neurálgico.

Iten, que no se puedan sacar ni saquen fuera destos reinos pan, ni los cueros de Sevilla. Y que se revoquen y den por ningunas las merçedes enquisiçiones que se dieron e ympusieron en algunas partes destos reinos de llevar çiertos derechos por dar liçençia para sacar pan fuera de ellos, e para sacar los cueros, e de la dicha çiudad de Sevilla. Porque demás de ser inpusiçión mala, es muy gran daño e perjuiçio destos reinos e de la dicha çiudad de Sebilla ${ }^{40}$.

Como es sabido, Sevilla, no se sumo al levantamiento y sus representantes no estuvieron en la elaboración de estos capítulos ${ }^{41}$. Sin descartar en sus redactores una concepción general del bien común del conjunto del reino, parece claro que estaban al corriente de que las exportaciones incidían en el precio del cereal no sólo en la capital hispalense, sino en buena parte de la Corona de Castilla.

Se trata, por tanto, de un problema que tiene su origen en decisiones políticas e intereses particulares, como también los hay en la especulación en el mercado del cereal. Se hace preciso, en todo caso, valorar su impacto relativo poniéndolo en relación con el resto de factores que generaron ciclos de carestía.

${ }^{38}$ Ibidem, p. 24; Chevet, O’Grada 1999, pp. 16-19. En la misma línea, aunque para fechas más tempranas Benito 2011, pp. 148-155.

${ }^{39}$ Arízaga 1985; Añibarro 2009, p. 371.

${ }^{40}$ Biblioteca Nacional. Ms. 1779, f. 154v.

${ }^{41}$ Pérez 1981, p. 393. 


\section{SOBRE LA GRAVEDAD RELATIVA DE LAS CARESTÍAS: PRECIOS DEL TRIGO EN BURGOS}

La existencia de correlación de precios entre dos lugares tan distantes como Sevilla y Burgos, al menos en momentos de carestía, permite añadir dimensiones complementarias al estudio de la propia serie de precios burgalesa, la más completa de las que disponemos. Esto permite efectuar valoraciones acerca de la gravedad relativa de las distintas carestías que se experimentaron y analizar los factores de mayor peso en la fluctuación al alza del precio del trigo, determinando en que medida están relacionados con la producción local o con el impacto de coyunturas concretas en el conjunto del reino.

Tabla 2. Precios y producción de cereal en Burgos y denuncias en Cortes

\begin{tabular}{|c|c|c|c|c|}
\hline & $\begin{array}{c}\text { PICO PRECIO } \\
\text { REALES/FANEGA }\end{array}$ & $\begin{array}{c}\text { CAÍDA } \\
\text { PRODUCCIÓN }\end{array}$ & $\begin{array}{l}\text { BUEN } \\
\text { AÑO }\end{array}$ & DENUNCIAS EN CORTES \\
\hline 1417 & 3,33 & & & \\
\hline 1418 & 3,00 & & & \\
\hline 1419 & 2,85 & & & \\
\hline 1420 & 3,57 & & & \\
\hline 1421 & & & & \\
\hline 1422 & 6,00 & & & Sacas \\
\hline 1423 & 3,35 & $X$ & & \\
\hline 1424 & 5,42 & & & \\
\hline 1425 & 3,85 & & & Especulación \\
\hline 1426 & 3,28 & & & \\
\hline 1427 & 2,00 & & $X$ & \\
\hline 1428 & 2,00 & & $X$ & \\
\hline 1429 & & & $X$ & \\
\hline 1430 & 2,14 & & $\mathrm{X}$ & \\
\hline 1431 & 2,42 & & $\mathrm{X}$ & Mercados francos \\
\hline 1432 & 2,57 & & $X$ & \\
\hline 1433 & 2,57 & & $X$ & \\
\hline 1434 & 4,13 & & $X$ & \\
\hline 1435 & 3,00 & $X$ & & Impacto fiscalidad \\
\hline 1436 & 2,81 & & $\mathrm{X}$ & \\
\hline 1437 & 2,35 & & & \\
\hline 1438 & 5,71 & $\mathrm{X}$ & & Sacas \\
\hline 1439 & 4,7 & $\mathrm{X}$ & & \\
\hline
\end{tabular}

Fuente: Casado 1991. 
La tabla 2 pone en relación los datos de producción y precios de que disponemos para Burgos, entre 1417 y 1439, con las denuncias efectuadas en Cortes relativas al problema de la carestía y permite efectuar una primera aproximación respecto de los factores que desequilibraron el precio del trigo en esta zona. En aquellos años, el precio medio de la fanega de trigo se situó en 3,08 reales. En los veintidós años que recoge la tabla, el precio de la fanega de cereal superó los cuatro reales en cinco ocasiones. El aspecto más llamativo es que los picos máximos del precio del cereal se alcanzan coincidiendo con denuncias en Cortes de exportación de cereal.

El precio más alto se alcanzó en 1422, en paralelo al ciclo de crisis en Andalucía que hemos analizado. Desconocemos el alcance de la cosecha de 1421. En todo caso, es bastante significativo que el precio de 1424, bajo la influencia de una mala cosecha en Burgos el año anterior, siendo alto, no alcanzara el nivel de precios del año 1422 .

La situación se reproduce en el año 1438. Coincidiendo con una nueva denuncia de saca en Cortes, se alcanzó el segundo pico máximo y el precio se situó en 5,71 reales la fanega ${ }^{42}$. Sin embargo, el año agrícola anterior no fue necesariamente malo. Ese año sí hubo una mala cosecha, pero en 1439 y quizá también ante una expectativa de otra mala cosecha ese verano, el precio, siendo alto, descendió hasta los 4,7 maravedíes la fanega ${ }^{43}$. La retirada de las licencias de saca tras la denuncia en Cortes permite explicar este comportamiento.

Por contra, los efectos de una mala cosecha en el campo burgalés no parecen sentirse de manera tan dramática en los precios. Así por ejemplo, pese a que el año de 1435 fue malo, los precios bajaron en 1436. El resto de denuncias en Cortes sobre los fenómenos que inciden en la carestía no parece tener una correlación exacta en la serie de precios burgalesa.

Sin duda, determinar los múltiples factores que pueden incidir en el precio del cereal es complejo, aunque esto no impide resaltar dos cuestiones. En primer lugar, los picos máximos de precio en Burgos se encuentran más relacionados con la concesión de licencias de saca y los efectos especulativos que provocan que con la propia producción del entorno burgalés. En segundo lugar, que el impacto de estos fenómenos en los precios es incluso mayor que el de una mala cosecha en la comarca.

El análisis de la serie completa de los precios en Burgos no sólo confirma esta primera hipótesis, sino que corrobora que los motivos que propiciaron el alza de precios en la capital burgalesa, más que relacionados con la

\footnotetext{
${ }^{42}$ Cortes, vol. III, p.345.

${ }^{43}$ Las referencias a la producción en Casado 1991,pp. 73 y ss.
} 
producción, fueron de índole política. La evolución de los precios del cereal expresada en reales permite además efectuar una valoración del impacto relativo de los episodios de carestía que afectaron a la capital burgalesa, dado que no se refleja el efecto de la devaluación del maravedí.

\section{Gráfico 2. Precios del trigo en Burgos}

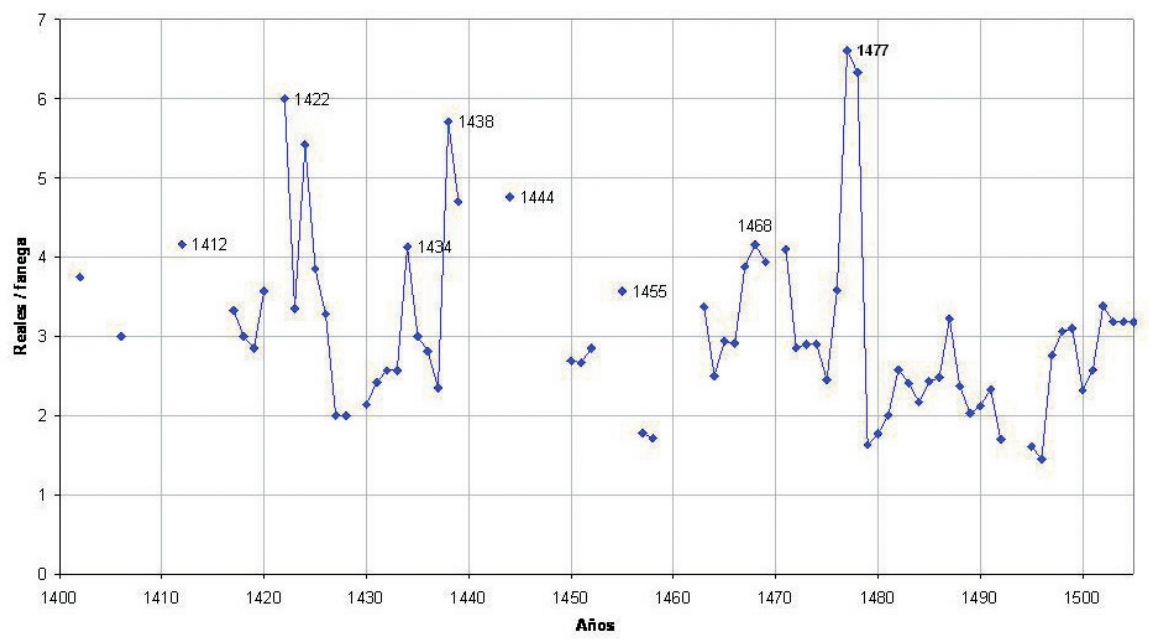

Fuente: Casado 1991. Elaboración propia.

Tal y como hemos referido, en la primera mitad del XV existe una fuerte correlación, entre los años en que los precios del cereal se disparan y las evidencias de exportación de cereal: 1412, 1422 y 1438, con la salvedad hecha que el año 1412 no reflejaría el pico de precios de este ciclo de carestía, que debería haberse alcanzado en años posteriores.

Aunque menor, el año de 1434 supone otro momento de escalada del precio del cereal. Tanto ese año como el anterior fueron años de relativa bonanza y sin embargo el precio del cereal alcanzo niveles muy superiores a los de 1435, año de baja producción, y a los de $1436^{44}$. Las razones para justificar esta alza de precios habría que buscarlas nuevamente en la interrelación de mercados. La crónica de Juan II refiere 1434 como un año de gran pluviosidad con un impacto negativo en la producción agraria, al dificultar las siembras. Las lluvias en los dos últimos meses del año propiciaron avenidas y desbordamientos en ciudades no demasiado lejanas de Burgos, como Valla-

\footnotetext{
${ }^{44}$ Casado 1991, p. 73.
} 
dolid, Medina del Campo y Madrid. En este último lugar, con referencias a hambre ${ }^{45}$. Ciudades más lejanas, como Sevilla también se vieron afectadas por este fenómeno ${ }^{46}$. La carestía en lugares más o menos cercanos parece, en este caso, influenciar el precio burgalés. Probablemente, los efectos más agudos se dejaron sentir en muchos lugares en 1435, tal y como evidencia la serie de precios de Sevilla, y sin embargo en Burgos, a pesar de que la cosecha no fue buena, los precios descendieron. La explicación más probable es que es lo que está detrás de la subida de precios es la propia expectativa de una futura mala cosecha, que puede cumplirse sólo parcialmente.

El alza del precio del trigo en 1444 puede bien obedecer a motivos locales, dado que la cosecha de 1443 fue mala en Burgos, aunque el trigo no llegó al nivel de precios que se verifica cuando concurren situaciones de licencia de $\mathrm{saca}^{47}$.

La tendencia general de la segunda mitad de siglo es la de unos precios más bajos e incluso, si exceptuamos el periodo crítico de los años 14761478 , también los picos de precios son menos elevados que en la primera mitad de siglo. El patrón es consistente con lo que conocemos para otros lugares, como Andalucía ${ }^{48}$.

Sin embargo, el factor más llamativo es la manera en que en esta segunda mitad de siglo la serie de precios aparece también relativamente desvinculada de la producción de la comarca. Así pues, el año de 1455, en un contexto de buena producción, coincide con nuevas denuncias de saca en Cortes ${ }^{49}$. El dato de precios de 1463 puede interpretarse desde una óptica similar, dado que las Cortes de 1462 habían denunciado ya que la saca provocaba carestía en Andalucía ${ }^{50}$.

Los años entre 1467 y 1469 coinciden con una cierta baja de las rentas decimales del cabildo catedral de Burgos. El efecto de la guerra civil parece haberse dejado sentir, si no en el propio volumen de la cosecha, al menos en la recogida de rentas del cabildo ${ }^{51}$. Sin olvidar que esos años fueron de escasez aguda también en Andalucía ${ }^{52}$, el impacto en los precios de las alteraciones monetarias. Este último aspecto, aparece reflejado en la cronística. Así, la Crónica anónima de los Reyes Católicos, refiere cómo:

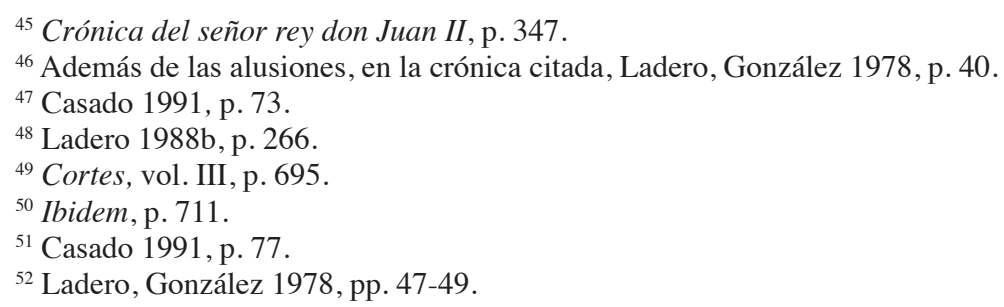


Por los caminos no hallaban que comer los caminantes por la moneda que nin buena nin mala nin por ningund precio non la tomaran los labradores (...) de la grand confusión y desorden de las monedas, vinieron las cosas tan caras en el reyno, que de aquel mal estilo dentonces, oy siempre durara el daño, syn remedio de tornar a los precios convenibles que solia ${ }^{53}$.

Respecto de los años 1477-1478, el volumen de las rentas recogidas apunta a cosechas inferiores a la media, aunque en todo caso, fueron similares a las del periodo crítico de 1467-1469. Sin embargo, los precios fueron considerablemente superiores y se dispararon hasta alcanzar los picos de precio más altos del siglo, coincidiendo con un nuevo ciclo de concesión de licencias de exportación desde Andalucía, probablemente las de mayor cuantía para el XV.

El episodio ha sido analizado con detalle para Sevilla por Miguel Ángel Ladero y Manuel González, que coinciden en que, si bien la cosecha de 1477 fue muy deficitaria, el factor principal causante de la carestía fue la multiplicación de las licencias de saca ${ }^{54}$. No está de más recordar cómo en marzo de 1478 es el propio concejo sevillano el que alude a la saca como causante de la carestía: la mengua e carestía procede de la dicha saca del dicho pan que continuamente se hace ${ }^{55}$.

Sólo para los años entre 1477 y 1478, las licencias que se conservan en Simancas refieren la salida de más de 192.000 fanegas del arzobispado de Sevilla y obispado de Cádiz, las más de ellas con destino a los mercados internacionales ${ }^{56}$. Algunas concesiones se explican por las necesidades de la política exterior de la monarquía. Aunque, en mayor medida, sus beneficiarios fueron gentes del entorno regio que vieron recompensados los servicios prestados a la causa. A tal punto, que el cronista Palencia ironiza para este momento con el tráfico de licencias en el entorno de la corte ${ }^{57}$. Es el impacto de estas concesiones y la espiral que desatan lo que explica el alza de precios y no sólo en Andalucía, puesto que el trigo alcanzo el precio máximo del siglo en el mercado burgalés.

En suma, la contextualización de los episodios en que el trigo alcanzó los mayores precios en el mercado burgalés durante el siglo XV nos aleja

\footnotetext{
${ }^{53}$ Crónica incompleta ed. Puyol, p. 96.

${ }^{54}$ Ladero, González 1978, pp. 81-85. El mal año agrario de 1477 en la Baja Andalucía se confirma con los datos aportados por González 1980, p. 139.

${ }^{55}$ Carande, Carriazo 1968, vol. II, p. 52.

${ }^{56}$ AGS. RGS.VI-1477, f. 256; VI-1477, f. 490; VIII-1477, f. 436; XI-1477, f. 259; II-1478, f. 41; II-1478, f. 43; II-1478, f. 127; II-1478, f. 42; II-1478, f. 44; III-1478, f. 46; IV-1478, f. 41; IV-1478, f. 43; V-1478, f. 83; VII-1478, f. 53; VII-1478, f. 54. Referencias adicionales sobre saca en Montes 2007, pp. 175-180.

${ }^{57}$ Ladero, González 1978, p. 84
} 
de la idea de la producción agraria como factor determinante en estos ciclos de carestía. No se trata de evacuar absolutamente la incidencia que pueda tener un año de producción deficitaria, aunque parece claro que los factores que tuvieron mayor impacto en los picos máximos de precio fueron de tipo político. Desde luego, el episodio de la guerra civil y las alteraciones monetarias, pero también y muy especialmente las licencias de saca.

La concesión de licencias de saca parece desatar mecanismos especulativos más agudos que las malas cosechas y se dejan sentir en Burgos, por más que en la mayor parte de los casos las evidencias de exportación apunten a Andalucía. Ni que decir tiene que una mala cosecha potenciará los efectos multiplicadores. En último término, el impacto de las licencias de saca parece afectar, a un nivel de escala que es difícil de determinar, al conjunto del reino. Se trata de una cuestión relevante, puesto que la historiografía ha centrado sobre todo su atención en el funcionamiento de los mercados locales de cereal. Los mecanismos especulativos operan a escala local, pero los factores desencadenantes en las crisis más agudas pueden situarse bastante más lejos, en el marco de una integración de mercados mayor de la que tradicionalmente se ha supuesto, lo que nos obliga a desplazar el foco de análisis.

El impacto de factores políticos viene a cuestionar además una narrativa lineal respecto de los progresos de la institución monárquica en la regulación del mercado del grano, ya que muestra a la propia monarquía como actor principal en la alteración de este marco regulador. Sin duda, la especulación ligada a estos procesos es un factor clave, pero está claro que la determinación de las condiciones (o la falta de ellas) en que se efectúa el comercio del cereal es una cuestión de regulación del mercado y remite en último término a un problema de tipo político.

El marco normativo que regulaba el mercado interior del cereal había quedado ya definido a comienzos del siglo. En una ley promulgada en las Cortes de Guadalajara de 1390 se estableció definitivamente la prohibición legal de exportación de oro, plata, moneda, cereal y caballos, pan y legumbres ${ }^{58}$. Quedaban exceptuadas las exportaciones efectuadas mediante licencia regia que, como hemos visto, los reyes otorgaron de manera profusa.

El otro elemento definitorio del marco normativo es la libertad de circulación de grano en el interior de Castilla, que fue establecida por Juan II en $1423^{59}$ y confirmada por Enrique IV en $1455^{60}$. En 1480, como consecuencia de la unión política, la libre circulación del grano se extendió a la Corona

${ }^{58}$ Cortes, vol. II, p. 442.

${ }^{59}$ Díaz de Montalvo 1986, libro 6, capítulo 9, ley tercera.

${ }^{60}$ Ibidem.

ANUARIO DE Estudios MEdievales, 46/2, julio-diciembre 2016, pp. 899-937 ISSN 0066-5061, doi:10.3989/aem.2016.46.2.10 
de Aragón ${ }^{61}$. Esta medida sería años más tarde denunciada por las ciudades en las Cortes Burgos de 1512, al entender que la autorización de las ventas a la Corona de Aragón producía efectos semejantes a los de las exportaciones en tiempos pasados. La monarquía confirmó, sin embargo, esta disposición, considerando que la unificación del espacio económico obedecía a una cuestión política $^{62}$.

En último término, la política monetaria, que dependía de la Corona, tuvo también su incidencia en el mercado del trigo. Este aspecto quedó particularmente puesto de manifiesto durante el reinado de Enrique $\mathrm{IV}^{63}$.

\section{PERCEPCIONES DE LA CARESTÍA Y LUCHA POLÍTICA}

Las orientaciones de la política cerealista, los mecanismos que regían el mercado del cereal y también las transgresiones de las normativas reguladoras fueron percibidas por los agentes implicados. Generaron denuncias, protestas y demandas de regulaciones adicionales que pueden seguirse a través de las reuniones de Cortes, en las que la carestía aparece de forma recurrente. Los procuradores de las ciudades instaron a los monarcas a tomar medidas que afectaban al mercado del grano, desatendidas en la mayor parte de los casos.

Bien entendido, las Cortes no funcionan como una institución estrictamente representativa, pues los procuradores se reclutan básicamente entre las élites locales ${ }^{64}$. Pero el discurso de los procuradores tiene sus propias condiciones de enunciación y no funciona como una mera traslación de los intereses de la élite. Pretende ser legítimo respecto de la ciudad a la que representa, lo que impone unas orientaciones y unos límites de actuación ${ }^{65}$. En suma, un discurso político que se presenta como representativo del bien conjunto de la comunidad y que puede incluso ser puntualmente contradictorio con los intereses de la propia élite local ${ }^{66}$.

Una primera línea de actuación en Cortes respecto de los precios del cereal tiene que ver con la constitución de stocks con fines especulativos. Su relación directa con la carestía fue denunciada ya en las Cortes de Palenzuela de 1425:

${ }^{61}$ Cortes, vol. IV, p.185.

${ }^{62}$ Ibidem, p. 241.

${ }^{63}$ MacKay 2006.

${ }^{64}$ Sobre la extracción social de los procuradores en Cortes, Carretero 1988.

${ }^{65}$ Sobre estas cuestiones puede acudirse a Ormrod 2009.

${ }^{66}$ Oliva, Challet, Dumolyn 2015. 
Se entremetían muchas personas cabdalosas a conprar pan, asi enlas cibdades o villas e lugares onde beuian commo en sus comarcas, e que lo encerrauan e esperauan alo rreuender a muchos mayores precios délo quelo conprauan, délo qual se rrecrescia mucha carestía en el pan $^{67}$.

Se solicitaba, en consonancia, que la monarquía facultara a las autoridades locales para decomisar esos stocks. Sólo unos años más tarde, en las Cortes de Madrid de 1433, los procuradores abordaron un problema directamente relacionado, el de la compra anticipada de cosechas vinculada al endeudamiento campesino, evocando tangencialmente su incidencia en la fijación de precios:

Quelos mis pecheros e naturales padecen muchos dannos por cabsa délos engannos queles son fechos por algunas personas, especialmente por que con sus menesteres venden adelantadamente por ser acorridos de dineros, los esquilmos de pan e vino, e a tan pequennos precios, quelos tales pecheros se pierden e despueblan $^{68}$.

La respuesta del rey a la primera demanda fue elusiva y en la segunda mostró de manera clara su negativa a intervenir, al afirmar respecto de las compras anticipadas quel conprar e vender es en libre facultad de cada vno, tanto que se non faga en enganno de vsura ${ }^{69}$. Ambas respuestas colocaban al rey del lado de los intereses de los poderosos.

En realidad, la especulación ligada al mercado del cereal era una práctica socialmente tolerada, al menos por lo que hace referencia a la doctrina eclesiástica. Un buen ejemplo lo proporciona el Libro de las Confesiones de Martín Pérez, donde se formula una condena general de la compra y almacenaje para la reventa a mayor precio, de la que se exceptúan expresamente las situaciones de carestía:

Empero ay dos maneras en que puede esto fazer sin pecado, conprar pan o vino refez e vender caro. La primera, si se conpra para mantenençia de la cassa e, despues las cosas conplidas, lo demas vendase por lo que val en aquel mercado. E puesto que vala el pan mas de lo que costo, non ay pecado (...) la segunda es quando manifiestamente paresçe que podra venir carestia de las viandas en la tierra (...) non con cobdiçia de ganar, mas como es dicho, para ayudar a su sennor Dios a mantener los sus fijos ${ }^{70}$.

${ }^{67}$ Cortes, vol. III, p. 72.

${ }^{68}$ Ibidem, p. 181.

${ }^{69}$ Ibidem.

${ }^{70}$ Pérez 2002, pp. 100-101. 
El discurso caritativo ofrece, por tanto, una legitimidad al acaparamiento y la reventa. De hecho, el conjunto de situaciones contempladas recorre todas las posibilidades que generaban prácticas especulativas, incluso la exportación del grano:

Quando vienen algunas tenpestades grandes, assi como guerras o si oviese sacar el pan para otras tierras o alguna cosa tal, con razon puede obrar la buena entençion, como es dicho ${ }^{71}$.

No será hasta el periodo de los Reyes Católicos cuando se detecten algunos cambios en la actitud monárquica hacia la especulación con el cereal. Así por ejemplo, en 1484, los Reyes facultaron al delegado regio en Medina del Campo para sacar al mercado a menor precio los excedentes retenidos con fines especulativos ${ }^{72}$. Igualmente, en 1497 se ordenó actuar al corregidor de Palencia, ya que los ricos e principales de la ciudad, guardaban trigo a la espera de que subiese su precio ${ }^{73}$. La propia tasa del trigo de 1502 se justifica mediante la condena de la especulación y su incidencia en el alza de precios ${ }^{74}$. En todo caso, tampoco los Reyes Católicos desarrollaron una política sistemática al respecto.

Estos mecanismos especulativos operaron a nivel local, a pesar de las políticas de abastecimiento desplegadas por las autoridades urbanas, amparadas bajo el principio legitimador del bien común ${ }^{75}$. La historiografía reciente ha subrayado la maleabilidad de este concepto, de modo que si bien podía haber cierto acuerdo respecto de determinadas políticas, la mención al bien común se utilizaba más bien como un referente discursivo que permitía articular las posiciones de unos y otros ${ }^{76}$. A este respecto, es ilustrativo el conflicto que se desató en Medina del Campo, en 1503, por el arrendamiento de la casa de la farina. Aludiendo al provecho del pueblo, el represente de la Comunidad solicitó que se adjudicara el arrendamiento a quien había efectuado la postura más baja ${ }^{77}$. La argumentación del regimiento iba en otra dirección: el servicio de la villa, consistía en garantizar su buen funcionamiento, por lo que los dos linajes medinenses se arrogaron la designación alternativa del servicio de la

${ }^{71}$ Ibidem.

${ }^{72}$ Oliva 2005, p. 14.

${ }^{73}$ AGS. RGS. VI-1497, f. 130

${ }^{74}$ Oliva 2007a, pp. 259-276.

${ }^{75}$ Entre los trabajos pioneros en esa dirección, Bonachía 1995; Martín 1996. Es de reseñar también el impacto de la obra de Peter Blickle, en particular de su artículo en castellano, Blickle 1998.

${ }^{76}$ Sobre estas cuestiones, Challet 2010; Dumolyn, Lecuppre-Desjardin 2010.

${ }^{77}$ Oliva 2005, pp. 16-17. 
casa de la farina, fuente nada desdeñable de negocio. La resolución de este caso concreto ilustra las limitaciones generales que envuelven las políticas municipales de abastecimiento, en las que a menudo se manifiesta esta tensión entre la lógica de la aprobación comunitaria y los intereses particulares.

Las políticas concejiles intentan canalizar al mercado urbano la producción del entorno rural y controlar el circuito intraurbano que garantiza su distribución. Dado que en la mayor parte de los casos la ciudad ejerce algún tipo de control político sobre su entorno rural, algunos concejos tomaron medidas para evitar que el cereal se viera desplazado por cultivos más rentables. Así, en Cuellar, se establecieron límites a la plantación de cultivos industria$\operatorname{les}^{78}$. O en Toledo, a comienzos del XV, se obligó a los cultivadores de vid a plantar una cantidad equivalente de cereal ${ }^{79}$. Pero la orientación productiva del espacio agrario era también objeto de enfrentamiento. En la propia Toledo, en 1493, el cabildo de jurados protestó por la proliferación de dehesas herbáceas con la consecuente falta de tierras labrantías que a su juicio incidían en la falta de aprovisionamiento de la ciudad y sin embargo proporcionaban importantes ingresos a la élite local ${ }^{80}$.

Fue bastante frecuente que se vetara la salida del grano de la jurisdicción de la ciudad, disposición prohibida por las leyes del reino desde 1423, lo que provocó enfrentamientos con las comunidades rurales del entorno ${ }^{81}$.

Por lo demás, muchas ciudades centralizan la compra venta en alhóndigas y se penaliza el comercio fuera de los lugares establecidos ${ }^{82}$. Tampoco es extraño que esté prohibida la compra a foráneos. Generalmente, se trata de potenciar la relación directa entre productores y consumidores, estableciendo un plazo de tiempo para facilitar la compra de pan a los vecinos antes de que caiga en manos de intermediarios, $u$ obligando a estos a vender durante unos días al precio de compra ${ }^{83}$. En definitiva, las disposiciones pueden ser diversas en las distintas ciudades, aunque la lógica subyacente es común. Pero las carestías continuaron produciéndose porque el problema de fondo estaba en otro sitio. El problema radica en que parte de la producción ni siquiera llega a ingresar el circuito de abastecimiento controlado por el concejo. Las ordenanzas

\footnotetext{
${ }^{78}$ Olmos 1998, pp. 255-256.

${ }^{79}$ Izquierdo 2002, p. 35.

${ }^{80}$ Ibidem, p. 37. Sobre el beneficio para las oligarquía toledana, Molenat 1997, pp. 498 y ss.

${ }^{81}$ Oliva 2005, p. 14.

${ }^{82}$ Por ejemplo, en Cuenca o Toledo, Sánchez 2008, p. 359; Izquierdo 2002, p. 155, respectivamente.

${ }^{83}$ Ibidem, pp. 186-188; Bennassar 1985, p. 162; Fuente 1987, p. 65. En otros lugares, como Cuenca, los concejos tratan de limitar el número de regatones sometiendo el desempeño de su oficio a autorización previa. Guerrero, Sánchez 1994, p. 195. Referencias a Zamora y Trujillo, en Colombo 2011, pp. 222-224.
} 
de la alhóndiga de Sevilla lo formulan con claridad en 1478, cuando aluden a la compra del pan en la alhóndiga por personas ricas y muy particularmente, que en momentos de crisis el pan que existe ni siquiera acude a la ciudad, esperando la llegada del pico de precios:

Cuando alguna esterilidad o necesidad de pan había, no se hallaba pan para vender en la alhóndiga y las personas que lo tenían no lo querían vender; y si lo vendían era secretamente y subiendo el precio en gran cuantía ${ }^{84}$.

Excepcionalmente hay algunas menciones en ordenanzas municipales que aluden a las compras anticipadas de cereal. Así por ejemplo, el fenómeno se prohíbe en las ordenanzas de Ávila ${ }^{85}$ y en las de Plasencia encontramos restricciones parciales ${ }^{86}$. Otras disposiciones, sin embargo, revelan lo habitual de esta práctica. En Cuenca, en un contexto de desabastecimiento, se conminó a traer a la ciudad el pan a aquellos que habían realizado compras por adelantado ${ }^{87}$. En Toledo se estableció que si se compraba pan por adelantado en su término, la venta debía de tener como destino la propia ciudad, aunque no se prohibió la práctica ${ }^{88}$. Quizá sorprenda menos el escaso tratamiento de la cuestión al considerar que entre sus beneficiarios figuraban miembros de las élites locales, convertidos en beneficiarios de rentas agrarias ${ }^{89}$. Además de la compra de tierra, la penetración de capital a través del crédito en el entorno rural posibilitaba la constitución de redes de dependencia, que incidían en la compra de grano y la fijación de precios ${ }^{90}$.

Algunos autores han abordado la relación entre el funcionamiento del mercado local y sus regulaciones políticas, resaltando los intereses en conflicto, como apuntara en su momento, José María Monsalvo ${ }^{91}$. Más recientemente, Octavio Colombo atribuye al imperfecto desarrolló del mercado la necesidad de reconocer la existencia de canales de comercialización más allá de la lógica reproductiva inherente a la fijación de precios políticos, resaltando el papel de los regatones como sujetos de prácticas especulativas ${ }^{92}$. Su brillante análisis ilumina, en parte, la lógica, aunque su modelo de mercado de

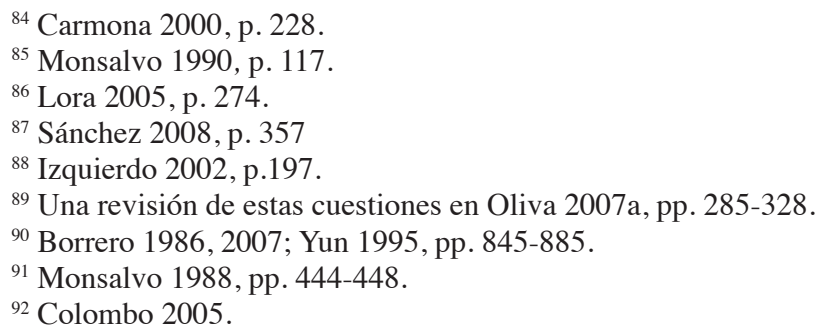


comercialización reducida de excedentes no es compartido por otros autores que contemplan de manera diferente las relaciones entre economía agraria y mercado y enfatizan además la capacidad de agencia de los propios productores agrarios ${ }^{93}$. Incluso estos podían tomar decisiones acerca de vender o no grano, a la espera de mejores precios, siempre y cuando dispusieran de cantidades suficientes.

Sin duda, intermediarios con elevada capacidad de compra tuvieron un papel protagonista en la especulación. Las menciones a regatones son relativamente abundantes en las ordenanzas municipales, aunque no parece tratarse de tratantes a gran escala. Las referencias en Cortes tienden a confirmar esta condición de intermediarios a pequeña escala ${ }^{94}$. De hecho, en ninguna de las ocasiones en las que se alude a la carestía se menciona a regatones como causantes. Antes al contrario, se habla de personas cabdalosas. En otros contextos documentales se reproduce el vocabulario cuando se denuncia la actuación de personas ricas o principales ${ }^{95}$, lo que sitúa el problema en otro nivel de escala: los grandes beneficiarios de la carestía son todos aquellos que pueden especular en el mercado del cereal, comenzado por los detentadores de rentas agrarias, intermediarios con importante capacidad adquisitiva y también, en contextos rurales, los hacendados locales ${ }^{96}$.

En suma, el conjunto de intereses anudados en torno al abastecimiento era demasiado complejo. Los poderes locales desplegaron políticas tendentes a favorecerlo, en las que sin embargo encontramos algunas zonas de sombra. También fueron los poderes locales quienes se ocuparon de solventar las situaciones más extremas ${ }^{97}$. La cuestión clave es hasta donde deben de subir los precios. Se trataba sin duda de garantizar la paz social, pero la actitud de las élites locales se mueve en este caso en una encrucijada entre la lógica del beneficio y la de la reproducción.

La documentación rara vez permite captar este juego de oposiciones que sin embargo quedan claramente iluminadas por la literatura. Son ilustrativas las referencias, algo tardías, ofrecidas por Diego de Guevara en sus Epístolas familiares. En una carta enviada a un caballero anónimo, ironizaba señalando que en lo que toma el avaro gusto es en no llover el abril y tener

\footnotetext{
${ }^{93}$ Una excelente revisión de estos aspectos en Furió 2011.

${ }^{94}$ Es significativo que las menciones a regatones y alza de precios aparezcan relacionadas con la compra de alimentos en las ciudades sede de la corte (Toledo 1462 y 1480), Cortes, vol. III, p. 710 y vol. IV, p. 90.

${ }_{95}$ AGS. RGS. VI-1497, f. 130.

${ }^{96}$ Sobre la cuestión de los campesinos ricos Oliva (en prensa).

${ }^{97}$ Respecto de las respuestas de las autoridades municipales en contextos de crisis frumentaria, Sánchez 2008, pp. 67-80; Oliva 2007b, pp. 259-276; Aguade 198; Goicolea 2011, p. 337 , entre otros. Para una comparación con la Corona de Aragón, Riera 2007 pp. 125-160.
} 
mucho trigo el mes de mayo ${ }^{98}$. En otra carta, dirigida a un regidor en 1522, le acusaba directamente al recordarle como habrá un año que me dijistes en Medina del Campo que teniades mill hanegas de trigo por si no llovía el mayo ${ }^{99}$. No se debe de observar contradicción alguna en esta actitud de las élites locales. La comparación respecto de las usurpaciones de términos comunales es ilustrativa a este respecto. Tales usurpaciones fueron condenadas recurrentemente por los gobiernos locales y denunciadas en Cortes, cuando precisamente miembros de la élite figuraban entre sus máximos beneficia$\operatorname{rios}^{100}$. La necesidad de que el ejercicio del poder aparezca como legítimo les obliga a condenar unas prácticas que llevan a cabo habitualmente de acuerdo a sus propios intereses ${ }^{101}$.

La carestía fue motivo de discusión en Cortes en otros contextos distintos. El primero de ellos tiene que ver con la competencia que se estableció con la creación por la alta nobleza de mercados francos en sus estados señoriales ${ }^{102}$. Las ciudades denunciarán entonces que estos mercados provocaban el encarecimiento de los mantenimientos al atraer los flujos comerciales.

Quelas viandas encarescen en vuestras cibdades e villas, ca las lieuan avender alos dichos sennorios, e principalmente por quel alcauala que se auia de fazer enlas dichas cibdades e villas délo que ende se solia vender se faga agora enlos dichos logares de sennores ${ }^{103}$.

La incidencia de esta situación en el precio es difícil de valorar. Posiblemente, la carestía es aquí invocada como un argumento para dotar de legitimidad a sus posiciones. En cualquier caso, no fue la única denuncia que se formuló respecto al interés de la nobleza de concentrar los flujos comerciales en sus estados señoriales. Es llamativo que en las peticiones de Cortes se aluda recurrentemente a caballeros e grandes omes, como principales transgresores de la normativa de libre circulación de cereal en el reino. Así, en las Cortes de Burgos del año 1453, se aludía a esta práctica situándola en el origen de la carestía:

${ }^{98}$ Guevara 1886, p. 164.

${ }^{99}$ Ibidem, p. 281.

${ }^{100}$ De hecho, a la altura de 1492, una pragmática de los Reyes Católicos reconocía respecto de los comunales que los propios gobernantes locales "ellos mismos toman e ocupan (...) mucha parte de los términos e propios e rentas de las dichas cibdades", citado por González 2001, p. 208.

101 Ibidem.

102 Sobre la cuestión de los mercados francos, Ladero 1994, pp. 102-103; Yun 1987, pp. 182-199.

${ }^{103}$ Cortes, vol. III, p. 90. 
Vedan la saca del pan (...) especialmente algunos caballeros e grandes omes e otras personas en los lugares de los señorios e por esta cabsa hay carestía de pan en muchos lugares de los vuestros dichos regnos ${ }^{104}$.

La denuncia se reproduciría dos años más tarde en términos similares en las Cortes de Córdoba de $1455^{105}$ y también en Toledo en $1462^{106}$.

La política monetaria fue también denunciada como causante del alza de precio. Es bien conocido que las reformas monetarias emprendidas por Enrique IV, en un sentido no siempre coherente, provocaron alteraciones importantes. En el contexto de la guerra civil, la proliferación de cecas y la acuñación de monedas de peor ley conservando el mismo curso legal, dispararon la inflación ${ }^{107}$. Detrás de estas medidas se encontraban las necesidades del monarca de conseguir efectivo suficiente para realizar sus pagos y la necesidad de atraer voluntades políticas mediante la concesión de cecas. Estas concesiones, que favorecían principalmente a la alta nobleza, multiplicaban el problema de la circulación de moneda de baja ley y propiciaban las falsificaciones ${ }^{108}$.

La situación sería denunciada en las Cortes de Ocaña de 1469, vinculando directamente el alza de precios con la circulación de moneda de baja ley:

La mala moneda que en estos rengos se labra e por el uso della e por el hundimiento que se haze públicamente de la moneda que esta fecha en menosprecio de dios e quebrantamiento de las leyes de estos regnos (...) una de las principales cosas que causan pobreza en las gentes e careza de todas las cosas ${ }^{109}$.

En último termino, en el marco de las políticas de reordenación monetaria emprendidas por Enrique IV a partir de 1471, el monarca terminaría decretando la intervención directa en el mercado de abastecimientos. En una carta enviada al reino en 1471, en la que se aludía a la corrupción de la moneda, a la subida de los precios y a la retracción de productos del mercado el monarca demandaba que:

Las personas que toviesen pan e vino e otros mantenimientos e mercaderias de vender, los apremiedes e costringadades que los

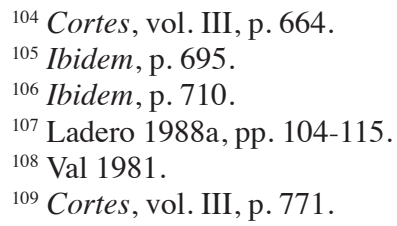


saquen a vender e los vendan públicamente por precio razonable $^{110}$.

Otra carta enviada en 1473 era todavía más explicita y emplazaba a las autoridades a forzar la venta de las mercancías ${ }^{111}$.

En todo caso, las reclamaciones más frecuentes se refieren a la exportación del cereal. La serie de denuncias en Cortes comienza en las Cortes de Ocaña de 1422, como referí, con una mención expresa a la salida de pan desde Andalucía. Algunos años más tarde, en Madrigal en 1438, se señala la gran carestía de pan, aludiendo a la climatología adversa y sus efectos sobre las cosechas, para después denunciar el fuerte incremento de la exportación

Por rrazon déla grand saca que se haze del dicho pan asi por mar commo por tierra para los regnos de Aragón e de Nauarra e de Portogal e para otras partes, el qual pan se saca en tanta suma e por tantas e tales maneras e con tanto afyncamiento, que en muchos lugares e comarcas de Andalozia e délas dichas fronteras de Aragón e de Nauarra e de Portogal de pocos dias aesta parte ha pujado e sobido la fanega del pan la meytad o las dos partes mas de quanto valia, e de dia en día puja e sube e pujará e subirá cada dia mas si enello remedio non se pone ... mande vedar la saca del $\operatorname{pan}^{112}$.

Desde luego, Andalucía no era el único punto desde el que se exportaba el cereal. Existía también un comercio terrestre de cereal hacia los vecinos reinos de Aragón y Navarra, que podía tener una incidencia en los precios en las comarcas más o menos cercanas ${ }^{113}$. También exportaciones por mar desde Murcia, aunque el volumen exportado no parece equiparable al que transita por vía marítima desde Andalucía ${ }^{114}$. Cabe recordar lo ya señalado, el impacto de las exportaciones que se realizan preferentemente desde Andalucía en el precio del trigo burgalés, tal y como reflejan especialmente los episodios de 1420-1422 y 1476-1478. Por lo demás, debió existir un tráfico habitual de exportación desde comarcas fronterizas, más o menos constante y, más o menos clandestino ${ }^{115}$. Pero lo que parece desatar el ciclo especulativo no es este

${ }^{110}$ Olivera 1986, vol. II, p. 357.

${ }^{111}$ Ibidem, p. 376.

${ }^{112}$ Cortes, vol. III, p. 345.

${ }^{113}$ Diago 2001, pp. 627-637. También, Sánchez 1993.

${ }_{114}$ Opinión compartida por Diago 2001, p. 633. Sobre las exportaciones de cereal desde Murcia, Quinteros 2009, pp. 387-405. p. 630 .

${ }^{115}$ Evidencias de comercio terrestre a pesar de las prohibiciones de saca en Diago 2001, 
tráfico, sino la concesión de licencias de saca, que suponen a la Corona una fuente de ingresos y sirven también para retribuir servicios políticos.

Este extremo se puso de manifiesto en las Cortes de Córdoba 1455, tras una nueva denuncia sobre la exportación de cereal a Portugal, Granada, Aragón y Navarra, y su impacto en los precios ${ }^{116}$. La respuesta otorgada por Enrique IV ilustra los límites en los que se mueve la política regia sobre la exportación, una normativa general prohibicionista constantemente vulnerada por el propio monarca mediante la concesión de licencias:

Por quanto yo tengo arrendados los diezmos e aduanas de los puertos de mys rreinos que son en fronteras de Aragón e Navarra por cierto tiempo e por ciertas condiciones (...) que aquellas sean guardadas e cumplidas durante el tiempo del dicho arrendamiento porque a mi no sea puesto descuento alguno en los maravedis que me an de dar por las dichas rentas ${ }^{117}$.

De hecho, no consta que promesa del monarca se cumpliera. En la siguiente reunión de Cortes, en 1462 en Toledo, el monarca volvió a ser acusado del encarecimiento del cereal, por las licencias otorgadas de exportación desde Andalucía:

De aquí adelante vuestra señoria no quiera dar cartas nin alvalaes nin mandamientos para sacar pan fuera de vuestros regnos, en especial a las que son en el Andaluzia, do es cierto que por cabsa de la dicha saca este año a avido asaz carestía en toda la tierra del Andaluzya $^{118}$.

En suma, un repaso por las peticiones de Cortes demuestra la consciencia que los habitantes de las ciudades tenían de que el problema del abastecimiento estaba fuertemente influenciado tanto por la especulación como por la exportación de cereal. Sus reclamaciones no consiguieron alterar la política de los distintos monarcas de manera sustancial, que sólo variará en algunos aspectos con la llegada al trono de los Reyes Católicos.

Parece claro que los perjudicados por estas políticas eran aquellos para los que el acceso a la compra de cereal entrañaba grandes dificultades a partir de cierto precio. Respecto a los beneficiarios de las licencias de saca, las concesiones efectuadas por los Reyes Católicos entre 1476 y 1478 son bastante ilustrativas. Al margen de licencias concedidas para favorecer relaciones

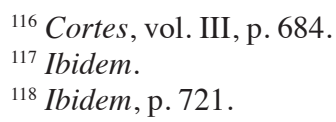


diplomáticas ${ }^{119}$, los principales beneficiarios fueron miembros de la aristocracia laica o eclesiástica, como el marques de Cádiz o el abad del convento de San Salvador de Jerez de la Frontera ${ }^{120}$, personajes como el Almirante Francisco Bocanegra ${ }^{121}$, y miembros del entorno regio como el Doctor Lillo o el contador Mayor Gutierre de Cárdenas ${ }^{122}$. A otro nivel de escala, miembros de las élites locales, que veían así retribuida su fidelidad a la Corona, como el representante en Cortes de la ciudad de Sevilla, el corregidor de Jerez de la Frontera o el Alcaide de Lebrija ${ }^{123}$. Por ultimo, grandes mercaderes obtenían directamente estas licencias o las compraban a sus concesionarios ${ }^{124}$. En suma, todo tiende a indicar que las licencias de saca funcionaban como un mecanismo más de concesión de rentas por parte de la monarquía.

En todo caso, llama la atención que en los momentos puntuales en que las ciudades estuvieron en disposición de ejercer un grado de autoridad política, proclamaron medidas directamente relacionadas con las denuncias en Cortes e incluso llegaron a ir más allá. Esto se produjo en dos momentos concretos: el primero, en 1467, en plena guerra civil castellana, cuando cristalizó la Hermandad General y el segundo durante el conflicto de las Comunidades. En ambos casos, la federación de ciudades, desarrollará una acción legislativa que incluye un programa de política económica.

Cierto es que, en estos momentos, la relación de fuerzas en las propias ciudades ha cambiado y el tradicional control ejercido por las élites locales se ha fracturado, al menos parcialmente. Este aspecto, bien conocido para el episodio comunero, ha sido recientemente tratado para las Hermandades Generales del periodo enriqueño ${ }^{125}$. Sólo desde esta perspectiva es posible entender las disposiciones adoptadas por la Hermandad para luchar contra el alza de precios de productos de primera necesidad en la Junta de Medina del Campo en 1467, que necesariamente tenían que entrar en conflicto con las posiciones de las elites locales.

Concretamente, los procuradores entendieron que el abastecimiento a precios razonables sufría a causa de la especulación y de los intereses de los grandes intermediarios. Su respuesta consistió, nada menos, que en la erradicación de las compañías comerciales: IV.

\footnotetext{
${ }^{119}$ AGS. RGS II-1478, f. 41. Licencia de saca de trigo de Castilla para Roma al Papa Sixto

${ }^{120}$ AGS. RGS V-1478, f. 83, VII 1476, f. 490.

${ }^{121}$ AGS. RGS VIII-1477, f. 436.

${ }^{122}$ AGS. RGS VI-1477, f. 256 y IV-1478, f. 43.

${ }^{123}$ AGS. RGS II-1478, IV, f. 42 y IV-1478, f. 81.

${ }^{124}$ AGS. RGS VI-1477, f. 256. Sobre esta cuestión, Quinteros 2009 pp. 393-405.

${ }^{125}$ Oliva 2014, pp. 330-345.
} 
Por quanto las compañías fechas en estas çibdades e villas e logares destos regnos de Castilla e Leon por los mercaderes vesinos de las dichas çibdades (...) se han causado grandes carestías en las mercaderías que se traen en los dichos regnos (...) en tal manera que las personas que han de comprar asy como para se vestir, como para su mantenimiento e las otras necesidades no lo pueden suplir ni soportar (...) porque seyendo grandes compañías (...) toman ansy todas las mercaderías e las sostienen en sy e non las quieren vender syn grand ganancia e yntereses. Que de aquy en adelante non se puedan faser las tales compañías (...) e que las fechas se desaten dentro de quatro meses ${ }^{126}$.

La disposición alude de forma general a los bienes de primera necesidad, pero incluye también una referencia a mantenimientos. A su lado, las medidas promulgadas por la Junta Comunera palidecen. Ya apuntamos que la prohibición de la exportación de grano, con particular referencia a Sevilla, figuraba entre los capítulos de la Junta en Tordesillas. Lo cierto es que la Junta había decretado la prohibición de la saca con anterioridad a la redacción de los capítulos y sus efectos en el precio del trigo fueron evidentes: después han prohibido la dicha saca y se halla que el precio del trigo ha diminuido por la mitad ${ }^{127}$.

Se trataba, en suma, de la puesta en práctica de una reivindicación tradicional, que había vuelto a formularse en las Cortes de la Coruña, que precedieron al estallido comunero ${ }^{128}$.

A margen de las reivindicaciones en Cortes, las tensiones inherentes a los ciclos de carestía y a las condiciones de funcionamiento del mercado del cereal provocaron además revueltas. Bien entendido que las dinámicas económica y política no son estrictamente equivalentes, ni siquiera los repertorios documentales que nos permiten dar cuenta de una y de otra.

En todo caso, existen evidencias de este tipo de conflicto en Sevilla y Jerez, centros principales de la exportación, donde el impacto debió ser más acuciante. Estos episodios se han contemplado demasiadas veces en clave irracional y poco consciente ${ }^{129}$, pero un análisis más pausado desvela que existe un conocimiento entre sus participantes de los mecanismos que operan en la coyuntura crítica y que determinan la selección de objetivos. Esto es, las formas de violencia no son sólo respuestas desesperadas que tratan de buscar pan a cualquier precio. Se trata más bien de actuaciones contra aquellos a los que se considera culpables de la carestía o a quienes se benefician de la especulación asociada a la crisis.

${ }^{126}$ Bermejo 1988, p. 389

${ }^{127}$ Dánvila 1897, p. 8.

${ }^{128}$ Cortes, vol. IV, p. 334.

${ }^{129}$ Cuestión que ya fue criticada por Neveux 1997, pp. 71-99. 
La crónica anónima de Enrique IV refiere una situación de este tipo en Sevilla en 1464, vinculando la acción popular a la actitud tomada por los notables de la ciudad en tiempo de crisis:

En Sevilla ovo grandes parçialidades y el pueblo era muy enemigo del arçobispo viejo, porque estando la tierra muy menguada de pan avia cargado muchas naos, algunos dizen para tierra de moros otros para otras partes por consentimiento del rey; e por el contrario avian grande amor al arçobispo nuevo, porque avia basteçido aquella çibdad e dado mucho de su pan a los pobres en el tienpo de la carestia. E asy el pueblo se levanto contra los prinçipales de la çibdad que favoresçian al arçobispo viejo ${ }^{130}$.

La relación de anales del jurado Garci Sanchez ofrece precisiones adicionales al señalar que en marzo de 1462 ya se había alterado la ciudad: se levantó un alboroto de hambre, que se armaron todos los más de la ciudad a buscar el pan donde estava ${ }^{131}$.

El problema principal radica en que, incluso en tiempos de carestía parece haber pan disponible, pero el destino que se le da es otro. Una situación parecida se produjo en Jerez en 1478, en pleno auge de la concesión de licencias de saca:

Por causa de la carestía del tiempo, algunos vecinos e moradores de la dicha ciudad y de su tierra han fecho y an causado algunos bullicios e escandalos e otros movimientos contra algunas personas ricas e abonadas de la dicha ciudad (...) a fin de les tomar sus bienes e les facer otros agravios en sus personas ${ }^{132}$.

Un patrón similar se reproducirá años después en Sevilla durante la crisis que sucedió a la implantación de la tasa del trigo en diciembre de 1502 . Casi tres años más tarde, en noviembre de 1505, en un momento agudo del ciclo, el concejo sevillano se dirigió al cabildo catedralicio para que pusiera a la venta pan de sus rentas:

Vosotros tenéys este presente año anno raçonable suma de pan de vuestras rentas; e commo quier que por su petiçión avéys sido requeridos que, dexando dello lo que avéys menester para la provisión de vuestras casas, lo demás lo vendiesedes a la dicha ciudad para la provisión de los vecinos della, diz que no lo avéys querido ni lo queréys hazer ${ }^{133}$.

${ }^{130}$ Crónica anónima de Enrique IV ed. Sánchez Parra, p. 135.

${ }^{131}$ Los anales de Garci Sánchez ed. Carriazo, p. 45.

${ }^{132}$ AGS. RGS, XII-1478, f. 16.

${ }^{133}$ Fernández, Ostos 2004, p. 403. 
La negativa del cabildo muestra que sus intereses eran otros. Sin embargo, en el entorno de la ciudad, los vecinos, conscientes de la existencia de stocks, habían procedido directamente a incautarlos:

Los vecinos de algunos lugares de la tierra se han atrevido a bos tomar el pan por su autoridad; e por ello los avéys descomulgado y puesto entredicho los dichos lugares ${ }^{134}$.

De todos modos, el episodio que muestra de forma más explicita el trasfondo de estos conflictos es la revuelta sevillana conocida como el Motín del pendón verde. Se trata de una algarada protagonizada por los vecinos de la zona norte de la ciudad, sobre la que un análisis reciente I. Knecevic aporta datos de interés ${ }^{135}$. El Discurso de la Comunidad de Sevilla, donde se relata la revuelta, refiere el fuerte incremento del precio del pan $^{136}$. Otras informaciones, revelan operaciones especulativas de compra de trigo en gran cantidad para su reventa a precios elevados ${ }^{137}$. Como respuesta, la gente comenzó a congregarse al toque de campana en busca de trigo almacenado y su primer objetivo fue uno de los jurados de la ciudad ${ }^{138}$. Claro que, los jurados sevillanos eran los oficiales supuestamente encargados de trasladar los intereses del común urbano ante las autoridades municipales. Incluso la simbología de la revuelta permite entrever el carácter político del movimiento, dado que los rebeldes se apropiaron del pendón verde que se custodiaba en la capilla de los Cervantes de la iglesia parroquial de Omnium Sanctorum. El miembro más destacado de esta familia, antiguo jurado en Sevilla y corregidor en Jerez de la Frontera, había sido el responsable de la concesión de numerosas licencias de exportación de grano ${ }^{139}$.

Finalmente, para resolver la situación las autoridades locales incentivaron la venta del cereal acaparado ${ }^{140}$, por lo que la carestía se resolvió una vez más con recursos locales.

El episodio muestra que los amotinados son conscientes de la lógica especulativa que rige en estas situaciones y buscan el trigo donde saben que está. Pero el contenido político se percibe con más claridad, ya que en este caso responsabilizan a algunos miembros de la élite local, que debían de velar por la estabilidad del precio del cereal y sin embargo se benefician de la situa-

\footnotetext{
${ }^{134}$ Ibidem.

${ }^{135}$ Knecevic 2014.

${ }^{136}$ Discurso de la Comunidad, p. 117.

${ }^{137}$ Knecevic 2014.

${ }^{138}$ Discurso de la Comunidad,p. 118.

${ }^{139}$ Knecevic 2014.

${ }^{140}$ Discurso de la Comunidad, p. 120.
} 
ción de carestía. En último término, lo que se fuerza también es una medida política, esto es, la intervención del gobierno urbano en el mercado para poner fin a la situación.

\section{CONCLUSIONES}

En suma, buena parte de las crisis frumentarias del XV parece estar más relacionadas con decisiones políticas y actuaciones humanas, que con las variaciones habituales de la producción agraria. Al margen de coyunturas específicas, ligadas a las alteraciones de la moneda, los momentos en los que el precio del grano alcanza niveles más elevados coinciden con las licencias de saca otorgadas por la monarquía. El efecto de interrelación de mercados determina que su impacto se perciba en lugares muy alejados. La especulación en el mercado del cereal se verifica de manera constante y se multiplica cuando se producen este tipo de concesiones.

Los contemporáneos fueron conscientes de estas vicisitudes. Denunciaron los mecanismos que propiciaban la especulación en el mercado del pan y solicitaron a la monarquía que adoptara medidas para corregirlos. Incluso en momentos críticos emprendieron acciones que muestran su conocimiento de los mecanismos que operan en la carestía, al apuntar directamente a los beneficiarios de la especulación en el mercado del grano.

En definitiva, detrás del fenómeno de las carestías durante el siglo XV se encuentra un conflicto de intereses perfectamente descrito en una máxima contemporánea recogida en el cancionero de Juan Fernández de Íxar: $S i$ as abundançia de pan, non cobdiçies carestia; por quanto el amador de la carestia homesçida de pobres cobdiçia ser ${ }^{141}$.

\section{BIBLIOGRAFÍA}

Aguadé Nieto, Santiago (1982), Crisis de subsistencia, rentas eclesiásticas y caridad en la Castilla de la segunda mitad del siglo XV, "En la España Medieval" 2, pp. 21-48.

Álvarez Vázquez, José Antonio (1984), Evolución de los arrendamientos agrícolas de 1450 a 1850 en Zamora, en Congreso de Historia Rural, siglos XV al XIX, Madrid, Casa de Velázquez, pp. 613-623.

${ }^{141}$ Cancionero de Juan Fernández de Íxar, citado de Banco de datos (CORDE). Corpus diacrónico del español [en línea]: http://www.rae.es [consulta: 15/06/2103]. 
Añibarro Rodríguez, Javier (2009), Producción, abastecimiento y consumo de las villa medievales de la costa cantábrica: el caso de Castro Urdiales, en Arízaga Bolumburu, Beatriz; Solórzano Telechea, Jesús Ángel (eds.) (2009), Alimentar la ciudad en la Edad Media, Logroño, Instituto de Estudios Riojanos, pp. 369-386.

Arízaga Bolumburu, Beatriz (1985), El abastecimiento de las villas vizcaínas medievales: política comercial de las villas respecto al entorno y a su interior, "En la España Medieval" 6, pp. 293-316.

Arízaga Bolumburu, Beatriz; Solórzano Telechea, Jesús Ángel (eds.) (2009), Alimentar la ciudad en la Edad Media, Logroño, Instituto de Estudios Riojanos.

Azáceta, José María (ed.) (1956), Cancionero de Juan Fernández de Íxar, Madrid, CSIC.

Benito i Monclús, Pere (2011), Las crisis alimenticias en la Edad Media: caracteres generales, distinciones y paradigmas interpretativos, en López Ojeda, Esther (ed.), Comer, beber, vivir: consumo y niveles de vida en la Edad Media hispánica.XXI Semana de Estudios Medievales, Logroño, Instituto de Estudios Riojanos, pp. 133-158.

Benito i Monclús, Pere (2013), De Labrousse a Sen. Modelos de causalidad y paradigmas interpretativos de las crisis alimentarias preindustriales, en Benito i Monclús, Pere (ed.), Crisis alimentarias en la Edad Media. Modelos, explicaciones y representaciones, Lleida, Milenio, pp. 15-31.

Bennasar, Bartolomé (1985), L'approvisionnement des villes de Castille aux Temps modernes, "Flaran" 5, pp. 155-164.

Bermejo Cabrero, José Luís (1988), Hermandades y Comunidades de Castilla, "Anuario de Historia del Derecho Español" 58, pp. 277-412.

Blickle, Peter (1998), El principio del bien común como norma para la actividad política: la aportación de campesinos y burgueses al desarrollo del Estado Moderno temprano en Europa Central, "Edad Media. Revista de Historia" 1, pp. 29-46.

Bonachía Hernando, Juan Antonio (1995), Abastecimiento urbano, mercado local y control municipal: la provisión y comercialización de la carne en Burgos (siglo XV), "Espacio, tiempo y forma. Serie III, Historia medieval" 5 , pp. 85-162.

Borrero Fernández, Mercedes (1986), Efectos del cambio económico en el ámbito rural. Los sistemas de crédito en el campo sevillano (fines del siglo XV y principios del XVI), "En la España medieval" 8, pp. 219-244.

Borrero Fernández, Mercedes (2007), Propiedad campesina y crisis agrarias. Andalucía a principios del siglo XVI, en Oliva Herrer, Hipólito Rafael; 
Benito i Monclús, Pere (eds.), Crisis de subsistencia y crisis agrarias en la Edad Media, Sevilla, Universidad de Sevilla, pp. 303-330.

Bourin, Monique; Carocci, Sandro; Menant, François; To Figueras, Lluis (2011), Les campagnes de la Méditerranée occidentale autour de 1300: tensions destructrices, tensions novatrices, "Annales. Histoire, Sciences Sociales" 3, pp. 663-704.

Bourin, Monique; Menant, François; Drendel, John (eds.) (2011), Les disettes dans la conjoncture de 1300 en Méditerranée occidentale, Roma, École Française de Rome.

Brunel, Sylvie (2002), Famines et politique, París, Presses de Sciences Politiques.

Carande, Ramón; Carriazo, Juan de Mata (eds.) (1968), El Tumbo de los Reyes Católicos del concejo de Sevilla, Sevilla, Universidad de Sevilla.

Carmona, José Ignacio (2000), Crónica urbana del malvivir (S. XIV-XVII). Insalubridad, desamparo y hambre en Sevilla, Sevilla, Universidad de Sevilla.

Carretero Zamora, Juan Manuel (1988), Cortes, monarquía, ciudades. Las Cortes de Castilla a comienzos de la época moderna (1476-1515), Madrid, Siglo XXI.

Carriazo Arroquia, Juan de Mata (1947), Anecdotario sevillano del siglo XV, Sevilla, Universidad de Sevilla.

Casado Alonso, Hilario (1991), Evolución de la producción agraria, precios y coyuntura económica en los obispados de Burgos y Palencia a lo largo del siglo XV, "Studia Historica. Historia Medieval” 9, pp. 67-110.

Challet, Vincent (2010), Le bien commun à l'épreuve de la pratique: discours monarchique et réinterprétation consulaire en Languedoc à la fin du Moyen Âge, "Revue Française d'Histoire des Idées Politiques" 32, pp. 311-324.

Chevet, Jean-Michel; O'Grada, Cormac (1999), Market Segmentation and Famine in Ancien Régime France, en Workshop on Historical Market Integration, Venecia, Venice International University, pp. 1-41.

Colombo, Octavio (2005), La naturaleza de los mercados campesinos en la baja Edad Media, “Anales de Historia Antigua, Medieval y Moderna" 37-38, pp. 155-86.

Colombo, Octavio (2011), El intercambio desigual en los mercados locales: formas de explotación comercial del campesinado en la Castilla del siglo XV, "Edad Media. Revista de Historia" 12, pp. 215-242.

Cortes de los antiguos reinos de Castilla y León (1868), 4 vols., Madrid, Real Academia de la Historia.

Crónica anónima de Enrique IV de Castilla 1454-1474 (1991), ed. María Pilar Sánchez Parra, Madrid, Ediciones de la Torre. 
Crónica del señor rey don Juan II (1789), ed. Lorenzo Galíndez de Carvajal, Valencia, Imprenta de Benito Monfort.

Crónica incompleta de los Reyes Católicos (1934), ed. Julio Puyol, Madrid, Real Academia de la Historia.

Dánvila Tortosa, Manuel (1897), Historia crítica y documentada de las Comunidades de Castilla. Memorial Histórico Español, vol. 36, Madrid, Real Academia de la Historia.

Devereux, Stephan (1993), Theories of famine, Londres, Harvester Wheatsheaf.

Diago Hernando, Máximo (2001), El comercio de productos alimentarios entre la Corona de Castilla y Aragón en los siglos XIV y XV, "Anuario de Estudios Medievales" 31/2, pp. 627-637.

Díaz de Durana, José Ramón (1986), Álava en la Baja Edad Media. Crisis, recuperación y transformaciones socioeconómicas (c. 1250-1525), Vitoria, Universidad del País Vasco.

Díaz de Durana, José Ramón (1990), La recuperación del siglo XV en el nordeste de la Corona de Castilla, "Studia Historica. Historia Medieval" 8, pp. 79-118.

Díaz de Montalvo, Alfonso (1986), Compilación de las leyes del reino, ed. facsímil, Valladolid, Lex nova.

Discurso de la Comunidad de Sevilla. Año de 1520, que escribió un clérigo apasionado de la Casa de Niebla (1881), Sevilla, Imprenta y librería española y extranjera.

Dumolyn, Jan; Lecuppre-Desjardin, Élodie (2010), Le bien commun en Flandre médiévale: une lutte discursive entre prince et sujets, en Lecuppre-Desjardin, Élodie; Van Bruaene, Anne-Laure (eds.), De Bono Communi. The discourse and practice of the Common good in the European City (13th-16th c.), Turnhout, Brepols, pp. 253-268.

Fernández Gómez, Manuel; Ostos Salcedo, Pilar (2004), El Tumbo de los Reyes Católicos del Concejo de Sevilla. XII (1503-1507), Madrid, Fundación Areces.

Fuente Pérez, María Jesús (1987), Palencia. Cien años de vida y gobierno de la ciudad (1421-1521) a través de las actas municipales, Palencia, Diputación de Palencia.

Furió Diego, Antoni (2011), Producción, pautas de consumo y niveles de vida. Una introducción historiográfica, en López Ojeda, Esther (ed.), Comer, beber, vivir: consumo y niveles de vida en la Edad Media hispánica. XXI Semana de Estudios Medievales, Logroño, Instituto de Estudios Riojanos, pp. 321-357.

Goicolea Julián, Francisco Javier (2011), Abasto y consuno de productos alimenticios en las ciudades y villas riojanas a fines de la Edad Media, 
en López Ojeda, Esther (ed.), Comer, beber, vivir: consumo y niveles de vida en la Edad Media hispánica. XXI Semana de Estudios Medievales, Logroño, Instituto de Estudios Riojanos, pp. 321-357.

González Alonso, Benjamín (2001), La reforma del gobierno de los concejos en el reinado de Isabel, en Valdeón Baruque, Julio (ed.), Isabel la Católica y la política, Valladolid, Ámbito.

González Gómez, Antonio (1980), Producción y precio de cereales en Trigueros (Huelva), 1450-1512, "En la España Medieval" 1, pp. 129-142.

Guerrero Navarrete, Yolanda; Sánchez Benito, José María (1994), Cuenca en la Baja Edad Media: un sistema de poder, Cuenca, Diputación provincial de Cuenca.

Guevara, Antonio de (1886), Epístolas familiares y escogidas, Barcelona, Biblioteca clásica española.

Izquierdo Benito, Ricardo (2002), Abastecimiento y alimentación en Toledo en el siglo $X V$, Toledo, Universidad de Castila la Mancha.

Knecevic, Igor (2014), The Green Banner of La Feria: Popular Revolt and Municipal Politics in Early Sixteenth-Century Seville, en Dumolyn, Jan; Haemers, Jelle; Oliva Herrer, Hipólito Rafael; Challet, Vincent (eds.), The Voices of the People in Late Medieval Europe. Communication and Popular Politics, Turnhout, Brepols, pp. 167-183.

Ladero Quesada, Miguel Ángel (1988a), La política monetaria en la Corona de Castilla (1369-1497), "En la España Medieval” 11, pp. 79-124.

Ladero Quesada, Miguel Ángel (1988b), El crecimiento económico en la Corona de Castilla en el siglo XV: algunos ejemplos andaluces, en Los mudéjares de Castilla y otros estudios de historia medieval andalu$z a$, Granada, Universidad de Granada, pp. 257-288.

Ladero Quesada, Miguel Ángel (1994), Las ferias de Castilla. Siglos XII al $X V$, Madrid, Comité español de ciencias históricas.

Ladero Quesada, Miguel Ángel; González Jiménez, Manuel (1978), Diezmo eclesiástico y producción de cereales en el reino de Sevilla (14081503), Sevilla, Universidad de Sevilla.

Llopis Agelán, Enrique (2001), El mercado del trigo en Castilla y León, 1691-1788. Arbitraje espacial e intervención, "Historia Agraria" 25, pp. 13-68.

Llopis Agelán, Enrique; Sotoca Pérez, Sonia (2005), Antes, bastante antes: la primera fase de la integración del mercado español de trigo, 17251808, "Historia Agraria" 36, pp. 225-262.

López Ojeda, Esther (ed.) (2011), Comer, beber, vivir: consumo y niveles de vida en la Edad Media hispánica.XXI Semana de Estudios Medievales, Logroño, Instituto de Estudios Riojanos. 
López Salazar, Jerónimo; Martín Galán, Manuel (1981), Producción cerealista en el arzobispado de Toledo (1463-169), "Cuadernos de Historia Moderna y Contemporánea” 2, pp. 21-101.

Lora Serrano, Gloria (2005), Ordenanzas municipales de la ciudad de Plasencia, Sevilla, Universidad de Sevilla.

Los anales de Garci Sánchez, jurado de Sevilla (1973), ed. Juan de Mata Carriazo, Sevilla, Universidad de Sevilla,

MacKay, Angus (1972), Popular Movements and Pogroms in fifthenth-century Castile, "Past and Present" 55, pp. 33-67.

MacKay, Angus (2006), Moneda, precios y política en la Castilla del siglo $X V$, Granada, Universidad de Granada - Universidad de Sevilla.

Martín Cea, Juan Carlos (1996), Poderes públicos y sociabilidad local en la villa de Paredes de Nava en el "Cuatrocientos", en Bonachía, Juan Antonio (ed.), La ciudad medieval: aspectos de la vida urbana en la Castilla bajomedieval, Valladolid, Universidad de Valladolid, pp. 255-316.

Menant, François (2007), Crisis de subsistencias y crisis agrarias en la Edad Media: algunas reflexiones previas, en Oliva Herrer, Hipólito Rafael; Benito i Monclús, Pere (eds.), Crisis de subsistencia y crisis agrarias en la Edad Media, Sevilla, Universidad de Sevilla, pp. 17-69.

Molenat, Jean-Pierre (1997), Campagnes et monts de Tolède du XIIe au XVe siècle, Madrid, Casa de Velázquez.

Monsalvo Antón, José María (1988), El sistema político concejil. El ejemplo del señorío medieval de Alba de Tormes y su concejo de villa y tierra, Salamanca, Ediciones Universidad.

Monsalvo Antón, José María (1990), Ordenanzas medievales de Ávila, Ávila, Institución Gran Duque de Alba.

Monsalvo Antón, José María (2001), Usurpaciones de comunales: conflicto social y disputa legal en Ávila y su Tierra durante la Baja Edad Media, "Historia Agraria" 24, pp. 89- 122.

Montes Romero-Camacho, Isabel (2007), Crisis de subsistencia y comercio exterior de cereales, en Oliva Herrer, Hipólito Rafael; Benito i Monclús, Pere (eds.), Crisis de subsistencia y crisis agrarias en la Edad Media, Sevilla, Universidad de Sevilla, pp. 161-197.

Neveux, Hugues (1997), Les révoltes paysannes en Europe (XIVe-XVIIe siècle), París, Albin.

Oliva Herrer, Hipólito Rafael (2005), Abastecimiento local y comercio cotidiano en Medina del Campo a fines de la Edad Media. Las ordenanzas del peso, Valladolid, Diputación de Valladolid - Museo de las Ferias.

Oliva Herrer, Hipólito Rafael (2007a), El mundo rural en la Corona de Castilla en la baja Edad Media: dinámicas socioeconómicas y nue- 
vas perspectivas de análisis, "Edad Media. Revista de Historia" 8, pp. 285-328.

Oliva Herrer, Hipólito Rafael (2007b), Reacciones a la crisis de 1504 en el mundo rural castellano, en Oliva Herrer, Hipólito Rafael; Benito i Monclús, Pere (eds.), Crisis de subsistencia y crisis agrarias en la Edad Media, Sevilla, Universidad de Sevilla, pp. 259-276.

Oliva Herrer, Hipólito Rafael (2014), ¡Viva el Rey y la Comunidad! Arqueología del discurso político de las Comunidades, en Oliva Herrer, Hipólito Rafael; Challet, Vincent; Dumolyn, Jan; Carmona Ruíz, María Antonia (eds.), La comunidad medieval como esfera pública, Sevilla, Universidad de Sevilla, pp. 315-355.

Oliva Herrer, Hipólito Rafael; Challet, Vincent; Dumolyn, Jan (2015), La communauté comme espace de légitimité politique: un bilan provisoire, en Genet, Jean-Philippe (ed.), La légitimité implicite, París, Publications de la Sorbonne, pp. 189-206.

Oliva Herrer, Hipólito Rafael (en prensa), Campesinos ricos, mercado y crecimiento económico en la Castilla del XV, en Furió, Antoni; GarcíaOliver, Ferran (eds.), Pautes de consum $i$ nivell de vida al mundo rural medieval, Valencia, Universidad de Valencia.

Olivera Serrano, Cesar (1986), Las Cortes de Castilla y León y la crisis del Reino (1445-1474). El registro de Cortes, Burgos, Congreso Internacional sobre la Historia de las Cortes de Castilla y León.

Olmos Herguedas, Emilio (1998), La Comunidad de Villa y Tierra de Cuellar a fines de la Edad Media, Valladolid, Universidad de Valladolid.

Ormrod, Mark; Dodd, Gwilym; Musson, Anthony (eds.) (2009), Medieval Petitions: Grace and Grievance, Woodbridge, York Press.

Palermo, Luziano (1997), Sviluppo economico e società preindustriali. Cicli, strutture e congiunture in Europa dal medioevo alla prima età moderna, Roma, Viella.

Pérez, Joseph (1981), La revolución de las Comunidades de Castilla, Madrid, Siglo XXI.

Pérez, Martín (2002), Libro de las confesiones. Una radiografía de la sociedad medieval española, edición, introducción y notas de Antonio García García, Bernardo Alonso Rodríguez, Francisco Cantelar Rodríguez, Madrid, Biblioteca de Autores Cristianos.

Persson, Karl Gunnar (2004), Grain Markets in Europe. 1500-1900. Integration and Deregulation, Cambridge, Cambridge University Press.

Quinteros Cortés, Javier (2009), Los Spinola, los Opertis, los Negro y los Rey: la influencia de los genoveses en el abastecimiento de una ciudad. El caso de Murcia en la segunda mitad el siglo XV, en Arízaga Bolumburu, Beatriz; Solórzano Telechea, Jesús Ángel (eds.), Alimentar la 
ciudad en la Edad Media, Logroño, Instituto de Estudios Riojanos, pp. 387-405.

Ravaillon, Martin (1987), Markets and Famines, Oxford, Clarendon Press.

Riera Melis, Antoni (2007), Crisis frumentarias y politicas municipales de abastecimiento en las ciudades catalanas durante la Baja Edad Media, en Oliva Herrer, Hipólito Rafael; Benito i Monclús, Pere (eds.), Crisis de subsistencia y crisis agrarias en la Edad Media, Sevilla, Universidad de Sevilla, pp. 125-160.

Salrach Marès, Josep Maria (2012), El hambre en el mundo. Pasado y presente, Valencia, Universidad de Valencia.

Sánchez Benito, José María (1991), Crisis de abastecimientos y administración concejil. Cuenca, 1499-1509, "En la España Medieval” 14, pp. 67-80.

Sánchez Benito, José María (1993), La corona de Castilla y el comercio exterior. Estudio del intervencionismo monárquico sobre los tráficos mercantiles en la Baja Edad Media, Madrid, Ciencia 3.

Sánchez Benito, José María (2008), Coyuntura económica y política mercantil urbana (Cuenca, siglo XV), "Edad Media. Revista de Historia" 9, pp. 343-377.

Sen, Amartya (1981), Poverty and Famines: an Essay on Entitlement and Deprivation, Oxford, Oxford University Press.

Val Valdivieso, María Isabel del (1981), Un motivo de descontento popular: el problema monetario en Castilla durante el reinado de Enrique IV, "Historia, Instituciones, Documentos" 8, pp. 151-170.

Yun Casalilla, Bartolomé (1987), Sobre la transición al capitalismo en Castilla. Economía y sociedad en Tierra de Campos (1500-1830), Valladolid, Junta de Castilla y León.

Yun Casalilla, Bartolomé (1995), Transacción mercantil y formas de transmisión de la propiedad territorial (informe sobre el mercado de la tierra en la España moderna), "Hispania" 191, pp. 845-85.

Yun Casalilla, Bartolomé (2004), Marte contra Minerva. El precio del imperio español, c. 1460-1600, Madrid, Crítica.

Fecha de recepción del artículo: julio 2013

Fecha de aceptación y versión final: diciembre 2014 